\title{
Cloud sensitivity studies for stratospheric and lower mesospheric ozone profile retrievals from measurements of limb-scattered solar radiation
}

\author{
T. Sonkaew ${ }^{1,2}$, V. V. $\operatorname{Rozanov}^{1}$, C. von Savigny ${ }^{1}$, A. $\operatorname{Rozanov}^{1}$, H. Bovensmann ${ }^{1}$, and J. P. Burrows ${ }^{1}$ \\ ${ }^{1}$ Institute of Environmental Physics, University of Bremen, Otto-Hahn-Allee 1, 28359 Bremen, Germany \\ ${ }^{2}$ Science Faculty, Lampang Rajabhat University, 119 Lampang-Maeta Rd., Lampang, 52100, Thailand
}

Received: 22 December 2008 - Published in Atmos. Meas. Tech. Discuss.: 24 February 2009

Revised: 17 September 2009 - Accepted: 21 September 2009 - Published: 4 November 2009

\begin{abstract}
Clouds in the atmosphere play an important role in reflection, absorption and transmission of solar radiation and thus affect trace gas retrievals. The main goal of this paper is to examine the sensitivity of stratospheric and lower mesospheric ozone retrievals from limb-scattered radiance measurements to clouds using the SCIATRAN radiative transfer model and retrieval package. The retrieval approach employed is optimal estimation, and the considered clouds are vertically and horizontally homogeneous. Assuming an aerosol-free atmosphere and Mie phase functions for cloud particles, we compute the relative error of ozone profile retrievals in a cloudy atmosphere if clouds are neglected in the retrieval. To access altitudes from the lower stratosphere up to the lower mesosphere, we combine the retrievals in the Chappuis and Hartley ozone absorption bands. We find significant cloud sensitivity of the limb ozone retrievals in the Chappuis bands at lower stratospheric altitudes. The relative error in the retrieved ozone concentrations gradually decreases with increasing altitude and becomes negligible above approximately $40 \mathrm{~km}$. The parameters with the largest impact on the ozone retrievals are cloud optical thickness, ground albedo and solar zenith angle. Clouds with different geometrical thicknesses or different cloud altitudes have a similar impact on the ozone retrievals for a given cloud optical thickness value, if the clouds are outside the field of view of the instrument. The effective radius of water droplets has a small influence on the error, i.e., less than $0.5 \%$ at altitudes above the cloud top height. Furthermore, the impact of clouds on the ozone profile retrievals was found to have a rather small dependence on the solar azimuth angle (less than
\end{abstract}

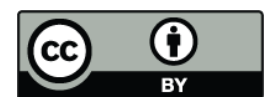

Correspondence to: $\mathrm{T}$. Sonkaew (thiranan@iup.physik.uni-bremen.de)
$1 \%$ for all possible azimuth angles). For the most frequent cloud types, the total error is below $6 \%$ above $15 \mathrm{~km}$ altitude, if clouds are completely neglected in the retrieval. Neglecting clouds in the ozone profile retrievals generally leads to a low bias for a low ground albedo and to a high bias for a high ground albedo, assuming that the ground albedo is well known.

\section{Introduction}

Clouds play an important role in the Earth's atmosphere. The tropospheric cloud coverage is about $50 \%$ at any given time and $7 \%$ of the total tropospheric volume is occupied by clouds (Lelieveld et al., 1989; Pruppacher and Jaenicke, 1995; Mace et al., 2007). Clouds interact with incoming solar radiation and long wavelength radiation emitted by the Earth, thus affecting the atmospheric energy budget and atmospheric photochemistry.

Tropospheric clouds affect the scattering and penetration of solar photons in the atmosphere (e.g., Vanbauce et al., 2003; Rozanov and Kokhanovsky, 2004). The scattering process impacts trace gas retrievals from satellite instruments or ground-based measurements (e.g., Erle et al., 1995; Rozanov and Kokhanovsky, 2008, and references therein).

Satellite observations of the scattered solar radiation in limb viewing geometry have become one of the standard techniques to measure stratospheric profiles of ozone and other minor constituents (e.g., McPeters et al., 2000; von Savigny et al., 2003; Haley et al., 2004; Rault, 2004). The limb-scatter observation geometry is characterized by a complex radiative transfer, because the multiple scattering or diffuse radiation contribution to the observed limb radiances

Published by Copernicus Publications on behalf of the European Geosciences Union. 


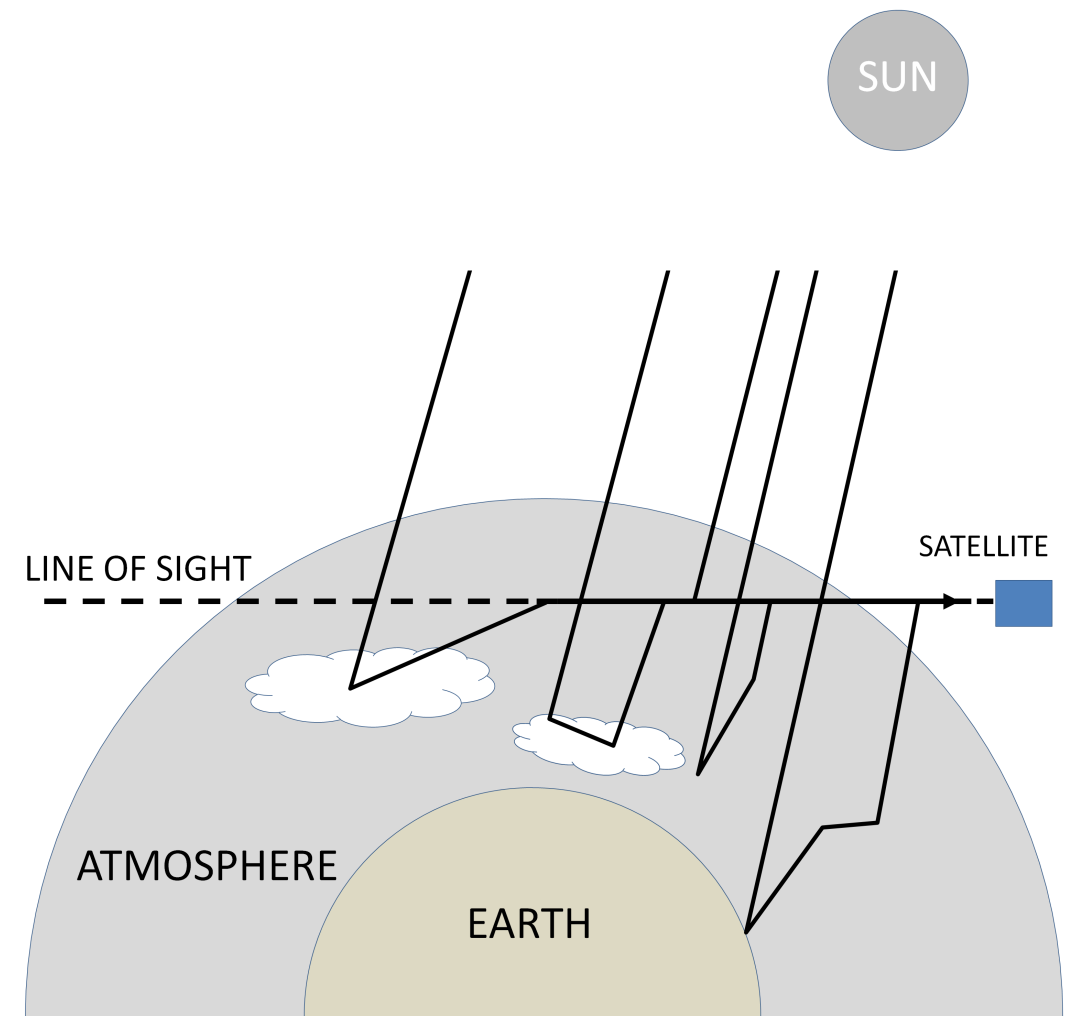

Fig. 1. A simple schematic diagram illustrating the limb-scatter observation geometry (not to scale).

can be significant (Oikarinen et al., 1999), and because the sphericity of the atmosphere cannot be neglected. Furthermore, the underlying surface, which may contribute significantly to the diffuse illumination of the sensed air volumes, is not observed directly. This geometry is strongly affected by surface albedo and clouds, especially in the spectral ranges with small gaseous absorption. Figure 1 illustrates the basic geometry of satellite limb-scatter observations. Although several recent studies presented detailed error analyses for stratospheric ozone profile retrievals from limb-scatter measurements (Haley et al., 2004; Loughman et al., 2005; von Savigny et al., 2005a), the effect of tropospheric clouds on the retrievals has not yet been comprehensively described or has been approximated by a high surface albedo in combination with an elevated Earth surface (e.g., Haley et al., 2004). In terms of stratospheric $\mathrm{NO}_{2}$ profile retrievals from satellite limb-scatter observations, Sioris et al. (2003) performed some sensitivity studies on the effect of clouds on the retrievals.

The main goal of this study is to investigate the effect of tropospheric clouds on the retrieval of ozone profiles in the stratosphere and the lower mesosphere from satellite measurements of the scattered solar radiation in limb viewing geometry. Ozone profile retrieval errors, due to neglect of clouds, are examined using a numerical method. The dependence of these errors on cloud optical and geometrical parameters, surface albedo, and viewing geometry (solar zenith and azimuth angles) are assessed. In the framework of this study, the following cloud parameters are considered: cloud optical thickness $(\tau)$, cloud top height, effective radius of water droplets $\left(r_{e}\right)$, and cloud geometrical thickness.

The structure of this paper is as follows: The methodology of our investigation and the software package SCIATRAN, which was used to obtain all presented results, are briefly discussed in Sect. 2. Section 3 describes the synthetic measurements used to derive the stratospheric and lower mesospheric ozone profiles from limb-scattered solar radiation exploiting both the Hartley and the Chappuis bands of ozone. In Sect. 4, the retrieval algorithm is summarized and the method to obtain the ozone retrieval error caused by neglecting clouds in the retrieval process is introduced. A method to estimate ozone retrieval errors based on a linear approximation is developed in Sect. 5. The atmospheric, surface and cloud scenarios employed throughout the study are described in Sect. 6. Section 7 discusses the reduction in cloud sensitivity of ozone profile retrievals if a wavelength triplet is used rather than single wavelengths. In Sect. 8, the influence of tropospheric clouds on the ozone profiles retrieved from limb-scatter measurements in both the Hartley and Chappuis absorption bands is investigated. The sensitivity studies are shown in terms of relative percentage errors of ozone profiles retrieved assuming a cloud-free atmosphere, although the (synthetic) measurements are made in a cloudy atmosphere. Finally, all results are summarized in the last section. 


\section{Methodology}

Due to a lack of detailed information on cloud properties in the observed part of the Earth's atmosphere, only qualitative investigations of the impact of tropospheric clouds on the accuracy of the ozone vertical profile retrieval are possible when real measured data are used. In this study, we employ an end-to-end numerical simulation technique allowing us to quantify the impact of tropospheric clouds of different kinds on the retrieval accuracy of ozone profiles in the stratosphere and lower mesosphere. The conceptual flow of our investigations is as follows:

1. We formulate the main scenario for the clear and cloudy atmosphere including typical vertical profiles of pressure, temperature, ozone number density, and surface albedo.

2. We formulate different cloud scenarios with various cloud parameters.

3. Using the radiative transfer code, we calculate the limb radiance spectra for these scenarios in the Hartley and Chappuis spectral absorption bands.

4. The simulated limb radiance spectra for cloudy conditions are considered as synthetic experimental data.

5. The vertical profile of ozone concentration is obtained ignoring cloudiness employing the retrieval algorithm as described in Sects. 3 and 4.

6. The retrieval errors are obtained for each cloud scenario by taking the difference between the retrieved ozone profile and the ozone profile used for the forward simulations (the true profile).

The described end-to-end approach requires the usage of appropriate algorithms to simulate the limb radiance spectra and to retrieve the ozone vertical profile. For this purpose, we have employed the software package SCIATRAN 2.2 (Rozanov et al., 2005b; Rozanov, 2008). This package incorporates a suitable radiative transfer model and the retrieval algorithm routinely run at the Institute of Environmental Physics of the University of Bremen to retrieve the vertical distributions of ozone in the stratosphere and the lower mesosphere from SCIAMACHY limb measurements. Throughout this study, the forward modelling is performed in an approximate spherical mode by employing the combined differential-integral (CDI) approach (Rozanov et al., 2001). With this approach, the outgoing radiance is calculated by integrating the contributions from both single and multiple scattering along the instrument line-of-sight intersecting a spherical shell atmosphere. The single scattered solar radiation is considered fully spherical. The multiple scattering contribution is approximated for each point at the line-ofsight by solving the pseudo-spherical radiative transfer equation for the proper atmospheric location and illumination.
The pseudo-spherical solution is obtained by employing the discrete-ordinate method similar to that described by Siewert (2000). The weighting functions are calculated by employing the forward-adjoint technique as described by Rozanov (2006).

The SCIATRAN software package compares well with other radiative transfer codes (Kurosu et al., 1997; Loughman et al., 2004; Hendrick et al., 2006; Wagner et al., 2007). It has been successfully employed to retrieve vertical profiles of atmospheric trace gases from measurements of the scattered solar radiation performed by the SCIAMACHY instrument in limb viewing geometry (Rozanov et al., 2005a; Bracher et al., 2005; von Savigny et al., 2005b; Butz et al., 2006; Rozanov et al., 2007).

\section{Forward simulations}

The vertical distribution of ozone number density in the Earth's atmosphere using limb-scatter measurements in the UV-Visible spectral range is commonly retrieved by exploiting the Hartley, Huggins, or Chappuis absorption bands. The Hartley bands in the UV have been employed by Rusch et al. (1983) to retrieve lower mesospheric ozone profiles from measurements with the UV spectrometer on Solar Mesosphere Explorer (SME). More recently, the Hartley bands were used by Rohen et al. (2006) to retrieve ozone profiles in the upper stratosphere and lower mesosphere from SCIAMACHY limb-scatter measurements. Ozone absorption in the Huggins bands was exploited for profile retrievals from limb-scatter measurements with the Shuttle Ozone limb-scattering Experiment/Limb Ozone Retrieval Experiment (SOLSE/LORE) flown on the space shuttle in 1997 and 2003 (Flittner et al., 2000; McPeters et al., 2000). The Chappuis bands in the visible have been used by Flittner et al. (2000), McPeters et al. (2000), von Savigny et al. (2003), Haley et al. (2004), Rault (2004), Rozanov et al. (2007) and Roth et al. (2007) to retrieve ozone profiles in the stratosphere from measurements with SOLSE/LORE, the Optical Spectrograph and InfraRed Imager System (OSIRIS) on Odin, the Stratospheric Aerosol and Gas Experiment (SAGE III) on Meteor-3, and SCIAMACHY. In this study, we combine the observations in the Hartley and Chappuis absorption bands to retrieve the vertical distributions of ozone in both the stratosphere and the lower mesosphere. A similar approach was recently applied to OSIRIS limb-scatter measurements (Degenstein et al., 2009), combining spectral information from the Hartley, Huggins and Chappuis bands in a simultaneous ozone profile retrieval. Furthermore, Tukiainen et al. (2008) recently presented retrievals of ozone profiles (and several other atmospheric parameters) from OSIRIS limb-scatter observations that also combined spectral information from the UV and visible ozone absorption bands.

In the Hartley absorption band, where the measured limb radiance is mostly sensitive to the ozone amount in the 
Table 1. The lowest $\left(h_{\text {low }}\right)$ and reference $\left(h_{r}\right)$ tangent heights for the wavelengths used.

\begin{tabular}{cccccccccccc}
\hline Wavelength $(\mathrm{nm})$ & 264 & 267.5 & 273.5 & 283 & 286 & 288 & 290 & 305 & 525 & 602 & 675 \\
\hline$h_{\text {low }}(\mathrm{km})$ & 52 & 52 & 52 & 45 & 45 & 45 & 45 & 35 & 9 & 9 & 9 \\
$h_{r}(\mathrm{~km})$ & 71 & 71 & 71 & 68 & 65 & 65 & 61 & 55 & 41 & 41 & 41 \\
\hline
\end{tabular}

$35-70 \mathrm{~km}$ altitude range, a discrete set of wavelengths is selected similarly to Rohen et al. (2006) avoiding Fraunhofer lines and dayglow emissions, namely, 264, 267.5, 273.5, 283, 286, 288, 290, and $305 \mathrm{~nm}$. To increase the signal to noise ratio, the limb radiance is averaged over $2 \mathrm{~nm}$ spectral intervals around each central wavelength. The UV wavelength set used in this study is somewhat smaller as compared to Rohen et al. (2006). In particular, we have skipped the three shortest $(250,252$, and $254 \mathrm{~nm}$ ) and the two longest (307 and $310 \mathrm{~nm}$ ) wavelengths. The former do not change the information content of the entire data set much and are strongly noise contaminated, whereas the latter are substantially affected by the multiple scattering and surface reflection. To reduce the impact of instrument calibration errors as well as of light scattering in the lower atmospheric layers, the limb radiance profiles at each wavelength are normalized by the limb radiance measured at an upper tangent height which is commonly referred to as the reference tangent height:

$I_{N}\left(\lambda_{k}, h_{i}\right)=\frac{I\left(\lambda_{k}, h_{i}\right)}{I\left(\lambda_{k}, h_{r}\right)}$.

Here, $I\left(\lambda_{k}, h_{i}\right)$ and $I\left(\lambda_{k}, h_{r}\right)$ denote the limb radiance at 8 wavelengths listed above, $\lambda_{k}, k \in\{1, \ldots, 8\}$ at the current, $h_{i}$, and the reference, $h_{r}$, tangent heights, respectively. At each wavelength only limb radiances observed in a selected tangent height range are used. Table 1 shows the lowest, $h_{\text {low }}$, and the reference, $h_{r}$, tangent heights for each wavelength, whereas the highest tangent height is always defined by the uppermost tangent height below the reference.

The spectral information obtained in the visible spectral range is treated by using the triplet approach following Flitther et al. (2000) and von Savigny et al. (2003) which exploits the limb radiance profiles at three wavelengths: $\lambda_{1}=525 \mathrm{~nm}$ at a relatively weak ozone absorption in the short-wavelength wing of the Chappuis band, $\lambda_{2}=602 \mathrm{~nm}$ at a strong ozone absorption near the center of the Chappuis band, and $\lambda_{3}=675$ at a weaker ozone absorption in the Chappuis bands. Similar to UV wavelengths, the limb radiance is averaged over $2 \mathrm{~nm}$ spectral intervals around each central wavelength and normalized by the limb radiance at the reference tangent height. The lowest, $h_{\text {low }}$, and the reference, $h_{r}$, tangent heights for the visible wavelengths are also listed in Table 1. Furthermore, the normalized limb radiance profiles are combined resulting in the so-called Chappuis triplet:

$I_{C h}\left(h_{i}\right)=\frac{I_{N}\left(\lambda_{2}, h_{i}\right)}{\sqrt{I_{N}\left(\lambda_{1}, h_{i}\right) I_{N}\left(\lambda_{3}, h_{i}\right)}}$.
Both the normalized limb radiances at UV wavelengths and the Chappuis triplet as given by Eqs. (1) and (2), respectively, will be denoted further as $y\left(h_{i}\right)$. For simplicity, we omit the explicit notation of the wavelength dependence.

Employing the SCIATRAN radiative transfer model, limb radiance spectra are generated in a cloudy and cloudfree atmosphere for all considered wavelengths and tangent heights. The vectors containing the limb radiances (normalized limb radiance profiles for the UV wavelengths and the Chappuis triplet) will be denoted as $y_{c}$ for cloudy, and $y_{f}$ for cloud-free conditions.

\section{Retrieval method and errors associated to clouds}

Obviously, the limb radiance in the considered spectral range depends on the vertical distribution of ozone in the atmosphere. Thus, any variation of the ozone number density in the altitude range where the applied measurement technique is sensitive, leads to a variation of the limb radiance detected by the instrument. Let us assume that $y_{c, f}^{\prime}\left(h_{i}\right)$ is obtained as a combination of measured limb radiances corresponding to the true ozone profile $n^{\prime}(z)$. Then applying the Taylor series expansion, $y_{c, f}^{\prime}\left(h_{i}\right)$ can be written as follows:

$y_{c, f}^{\prime}\left(h_{i}\right)=y_{c, f}\left(h_{i}\right)+\int_{0}^{H} \varpi_{c, f}\left(h_{i}, z\right) \delta n(z) d z+\varepsilon$.

Here, $y_{c, f}\left(h_{i}\right)$ are the limb radiances calculated for a cloudy (subscript $c$ ) or for a cloud-free (subscript $f$ ) atmosphere using the a priori ozone vertical profile $n(z), H$ is the top of atmosphere altitude, $\delta n(z)=n^{\prime}(z)-n(z)$ is the variation of the ozone number density profile, $\varpi_{c, f}\left(h_{i}, z\right)$ is the variational derivative of the appropriate limb radiance combination, as given by Eq. (1) or (2), with respect to the ozone number density, which is commonly referred to as the weighting function (see Rozanov, 2006, for further details):

$\varpi_{c, f}\left(h_{i}, z\right)=\frac{\delta y_{c, f}\left(h_{i}\right)}{\delta n(z)}$,

and $\varepsilon$ is the linearization error containing the contributions of higher-order terms of the Taylor series. We note that the weighting function for the gaseous absorber concentration as given by Eq. (4) is always negative because increasing the absorber concentration leads to increased light absorption and, hence, to decreasing limb radiance. 
If the cloudiness in the Earth's atmosphere is treated properly, the true vertical profile of ozone can formally be obtained from the corresponding radiances as follows:

$\hat{n}_{c}^{\prime}(z)=n(z)+\mathcal{R}_{c}\left[y_{c}^{\prime}\left(h_{i}\right)-y_{c}\left(h_{i}\right)\right]$,

where $\hat{n}_{c}^{\prime}(z)$ is the estimation of the true ozone vertical profile and $\mathcal{R}_{c}$ is the inverse operator whose explicit form depends on the applied retrieval algorithm. In particular, a nonlinear Newtonian iterative retrieval approach of the optimal estimation (Rodgers, 1976) type is employed throughout this study. The diagonal elements of the a priori covariance matrix were set to standard deviations of $1000 \%$ to ensure that the retrieval is completely independent of the a priori information. The off-diagonal elements were determined assuming a correlation length of $1.5 \mathrm{~km}$.

In a common retrieval process, $y_{c}^{\prime}\left(h_{i}\right)$ in Eq. (5) is obtained as a combination of the measured limb radiances whereas $y_{c}\left(h_{i}\right)$ is simulated with the forward model using the a priori profile $n(z)$. However, due to a lack of information about the cloud parameters in the observed scene, it is usually impossible to simulate $y_{c}\left(h_{i}\right)$ and $\mathcal{R}_{c}$ properly. The easiest way to avoid this problem is to neglect the clouds in the retrieval process assuming a cloud-free atmosphere when simulating the limb radiances and obtaining the inverse operator. This results, however, in a different estimation (compared to Eq. 5) for the true vertical distribution of ozone:

$\hat{n}_{f}^{\prime}(z)=n(z)+\mathcal{R}_{f}\left[y_{c}^{\prime}\left(h_{i}\right)-y_{f}\left(h_{i}\right)\right]$,

where, in contrast to $\mathcal{R}_{c}$, the inverse operator $\mathcal{R}_{f}$ is employed assuming a cloud-free atmosphere. Obviously, the absolute error in the retrieved vertical distributions of ozone occurring due to this approximation can be estimated as follows:

$\Delta n(z)=\hat{n}_{f}^{\prime}(z)-n^{\prime}(z)$,

where $n^{\prime}(z)$ is the true vertical profile of ozone which is known since the numerical simulation technique is used. For the sake of simplicity, the numerical experiments are performed throughout this study assuming that the true ozone number density profile is the same as a priori one, i.e., $n^{\prime}(z)=n(z)$ and $\delta n(z)=0$. Hence, following from Eq. (3), $y_{c}^{\prime}\left(h_{i}\right)=y_{c}\left(h_{i}\right)$, and Eq. (6) this results in

$\hat{n}_{f}^{\prime}(z)=n(z)+\mathcal{R}_{f}\left[y_{c}\left(h_{i}\right)-y_{f}\left(h_{i}\right)\right]$.

Substituting $\hat{n}_{f}^{\prime}(z)$ as given by Eq. (8) into Eq. (7) and taking into account that $n^{\prime}(z)=n(z)$, we obtain

$\Delta n(z)=\mathcal{R}_{f}\left[y_{c}\left(h_{i}\right)-y_{f}\left(h_{i}\right)\right]$.

Here, $\Delta n(z)$ characterizes the absolute retrieval error (retrieved minus true ozone number density) caused by neglecting the cloudiness in the retrieval process. In the following sections, we consider the relative error of the ozone vertical profile retrieval as given by

$r(z)=\frac{\Delta n(z)}{n(z)}=\frac{1}{n(z)} \mathcal{R}_{f}\left[y_{c}\left(h_{i}\right)-y_{f}\left(h_{i}\right)\right]$.

\section{Approximate approach to estimate the retrieval errors}

In the previous section, we have described an approach allowing us to calculate the error in the retrieved ozone profiles associated with neglecting clouds in the retrieval process. Unfortunately, the final expression for this error, Eq. (9), contains the inverse operator, $\mathcal{R}_{f}$, which, for the problem under consideration, does not have an analytical representation. Thus, for each considered atmospheric scenario, the inverse problem needs to be solved numerically. Furthermore, the complicated relationship between the observed limb radiance and the retrieved concentrations does not allow the obtained results to be easily explained. In this section, we derive an approximate expression which establishes a simple relationship between the observed quantities and the retrieval error of the ozone profiles allowing the latter to be estimated without solving the inverse problem.

One of the objectives of our discussion below is to illustrate how the normalization and combination of the limb radiances into the Chappuis triplet affects the sensitivity of the retrieval error to the tropospheric clouds. For this reason, in addition to the Chappuis triplet, we also consider the absolute limb radiance (i.e., not normalized) when discussing the approximate approach to estimate the retrieval error. On the other hand, it is clear that, because of the stronger extinction of the atmosphere, much less light penetrates down to the troposphere in the UV spectral region as compared to the visible range. Thus, the expected sensitivity of limb observations to tropospheric clouds is much weaker in the UV spectral range. For this reason, we do not consider the UV wavelengths when discussing the approximate retrieval error. Please note that the UV wavelenghts are considered when calculating the error employing the end-to-end numerical approach according to Eq. (9) or (10). For further considerations, let us introduce a new notation, $S_{c, f}\left(h_{i}\right)$, which will denote the Chappuis triplet, absolute limb radiance or normalized limb radiance for a cloudy and a cloud-free atmosphere, respectively. Further in the scope of this paper, $S_{c, f}\left(h_{i}\right)$ will be referred to as the limb signal.

Generally, retrieval errors due to neglect of clouds occur because the presence of clouds in the atmosphere causes changes in the limb signal similar to perturbations in the ozone vertical distribution. These retrieval errors can be estimated employing Eq. (3). To this end, let us rewrite this equation with the limb signals $S_{c}\left(h_{i}\right)$ and $S_{f}\left(h_{i}\right)$ corresponding to the cloudy and the cloud-free atmosphere on the left-hand and right-hand sides of Eq. (3), respectively. Equation (3) results in

$S_{c}\left(h_{i}\right)=S_{f}\left(h_{i}\right)+\int_{0}^{H} \varpi_{f}\left(h_{i}, z\right) \delta n(z) d z$ 
or

$\Delta S\left(h_{i}\right)=\int_{0}^{H} w_{f}\left(h_{i}, z\right) r_{\delta}(z) d z v$.

Here, $\Delta S\left(h_{i}\right) \equiv S_{c}\left(h_{i}\right)-S_{f}\left(h_{i}\right)$ is the variation of the limb signal caused by the cloud only because $S_{c}\left(h_{i}\right)$ and $S_{f}\left(h_{i}\right)$ were calculated using the same a priori ozone vertical density $n(z), r_{\delta}(z)=\delta n(z) / n(z)$ is the relative variation of the ozone number density caused by neglect of cloud and $w_{f}\left(h_{i}, z\right)$ is the corresponding weighting function that is usually referred to as the relative weighting function. Clearly, the relationship between the relative and absolute weighting functions is given by

$w_{c, f}\left(h_{i}, z\right)=\varpi_{c, f}\left(h_{i}, z\right) n(z)$.

Please note that, though the same notation is used, the weighting functions for the absolute limb radiance and for the Chappuis triplet are different.

It is worth noting that Eq. (11) states that the limb signal for a cloudy atmosphere and a priori ozone profile $n(z)$ is related to the limb signal for a perturbed ozone profile, i.e., $n(z)+\delta n(z)$, and a cloud-free atmosphere. We emphasize that the perturbation of the ozone vertical profile $\delta n(z)$ or $r_{\delta}(z)$ is a parameter to be found solving Eq. (11) or (12), respectively.

Approximating the relative variation of the ozone number density $r_{\delta}(z)$ in Eq. (12) by an altitude independent value $\bar{r}_{\delta}\left(h_{i}\right)$ as follows:

$\bar{r}_{\delta}\left(h_{i}\right)=\frac{\int_{0}^{H} w_{f}\left(h_{i}, z\right) r_{\delta}(z) d z}{\int_{0}^{H} w_{f}\left(h_{i}, z\right) d z}$,

it can be seen that Eq. (12) results in:

$\bar{r}_{\delta}\left(h_{i}\right)=\frac{\Delta S\left(h_{i}\right)}{W_{f}\left(h_{i}\right)}$,

where $W_{f}\left(h_{i}\right)$ is the vertically integrated weighting function defined by

$W_{f}\left(h_{i}\right)=\int_{0}^{H} w_{f}\left(h_{i}, z\right) d z$.

Thus, following Eq. (15), the approximate relative error in the ozone vertical distributions retrieved neglecting clouds in both forward model and the retrieval approach is proportional to the difference between the limb signals in a cloudy and a cloud-free atmosphere. This conclusion is in line with the results of the end-to-end numerical treatment given by Eq. (10).

A further simplification can be obtained using an approximate representation for $\Delta S\left(h_{i}\right)$ in Eq. (15). To obtain this approximation let us first expand the limb signal in a Taylor series similar to Eq. (3) restricting our consideration to linear terms:

$S_{c, f}\left(n^{\prime}\right)=S_{c, f}(n)+\int_{0}^{H} w_{c, f}(z) \frac{\delta n(z)}{n(z)} d z$.

Assuming that in the perturbed state, no ozone is present in the atmosphere, i.e., the perturbed vertical profile, $n^{\prime}(z)$, is equal to zero, the relative variation of the ozone concentration is written as

$\frac{\delta n(z)}{n(z)}=\frac{0-n(z)}{n(z)}=-1$

and Eq. (17) results in

$S_{c, f}(0)=S_{c, f}(n)-\int_{0}^{H} w_{c, f}(z) d z$,

where $S_{c, f}(n)$ and $S_{c, f}(0)$ are the limb signals with and without ozone absorption, respectively. Employing Eq. (19), the difference between the limb signals in a cloudy and a cloudfree atmosphere can be expressed as follows:

$S_{c}(n)-S_{f}(n)=\left[S_{c}(0)-S_{f}(0)\right]+\left[W_{c}-W_{f}\right]$.

or

$\Delta S(n)=\Delta S(0)+\Delta W$.

The first term on the right-hand side of Eq. (21) describes the variation of the limb signal due to the enhanced reflection of solar radiation by clouds in a non-absorbing atmosphere. The second term represents the variation of the gaseous absorption caused by changes in the photon path lengths in a cloudy atmosphere. We will refer to these terms, hereafter, as the scattering and absorption terms, respectively. Substituting $\Delta S(n)$ as given by Eq. (21) into Eq. (15), the following expression for the approximate retrieval error is obtained:

$\hat{r}_{\delta}\left(h_{i}\right)=\frac{\Delta S\left(h_{i} ; 0\right)+\Delta W\left(h_{i}\right)}{W_{f}\left(h_{i}\right)}$.

Although this equation provides a very convenient tool to analyze the retrieval error and allows the absorption by atmospheric trace gases and the reflection of light by clouds to be considered independently, it is affected by the quite strong limitation of the assumed linearity. In Sect. 7, we will consider a few examples showing that under certain conditions this limitation can lead to completely wrong results when estimating the retrieval error using Eq. (22).

\section{Atmospheric and cloud scenarios}

Throughout this study, the limb radiance is simulated in selected spectral intervals considering Rayleigh scattering, 
Table 2. Cloud parameter sets used in this study. The varied parameters are marked with $(\sqrt{ })$.

\begin{tabular}{|c|c|c|c|c|c|c|c|}
\hline \multirow[t]{2}{*}{ Sections/studied tests } & \multicolumn{6}{|c|}{ Cloud parameter } & \multirow[b]{2}{*}{ Figs. } \\
\hline & Cloud extension $(\mathrm{km})$ & $\tau$ & $r_{e}(\mu \mathrm{m})$ & SZA & SAA & A & \\
\hline \multirow[t]{2}{*}{ Absolute radiance vs. Chappuis triplet } & $4-7$ & 10 & 8 & 30 & 90 & 0.3 & Fig. 2, Fig. 3 \\
\hline & $4-7$ & 10 & 8 & 30 & 90 & 0.9 & Fig. 4 \\
\hline Investigation of the retrieval errors & $4-7$ & 10 & 8 & 30 & 90 & 0.3 & Fig. 5 \\
\hline \multicolumn{8}{|l|}{ Cloud types } \\
\hline - Low cloud & $1-3$ & $\sqrt{ }$ & 8 & 30 & 90 & 0.3 & Fig. 6a \\
\hline - Middle cloud & $2-7$ & $\sqrt{ }$ & 8 & 30 & 90 & 0.3 & Fig. $6 \mathrm{~b}$ \\
\hline - High cloud & $6-15$ & $\sqrt{ }$ & 8 & 30 & 90 & 0.3 & Fig. 6c, Fig. 6d \\
\hline Effective radius of water droplets & $2-7$ & 10 & $\sqrt{ }$ & 30 & 90 & 0.3 & Fig. 8a \\
\hline \multicolumn{8}{|l|}{ Cloud geometries } \\
\hline - Clouds top height & $\sqrt{ }$ & 10 & 8 & 30 & 90 & 0.3 & Fig. 9a \\
\hline - Cloud geometrical thickness & $\sqrt{ }$ & 10 & 8 & 30 & 90 & 0.3 & Fig. $9 \mathrm{~b}$ \\
\hline \multirow[t]{2}{*}{ Ground albedo } & $2-7$ & 10 & 8 & 30 & 90 & $\sqrt{ }$ & Fig. 10a, Fig. 11 \\
\hline & $2-7$ & 2 & 8 & 30 & 90 & $\sqrt{ }$ & Fig. $10 \mathrm{e}$ \\
\hline \multicolumn{8}{|l|}{ Viewing angles } \\
\hline$-\mathrm{SZA}$ & $2-7$ & 10 & 8 & $\sqrt{ }$ & 90 & 0.3 & Fig. 12a \\
\hline$-\mathrm{SAA}$ & $2-7$ & 10 & 8 & 30 & $\sqrt{ }$ & 0.3 & Fig. $12 b$ \\
\hline - SCIAMACHY limb-scan & $2-7$ & 10 & 8 & $\sqrt{ }$ & $\sqrt{ }$ & 0.3 & Fig. 14a \\
\hline - OSIRIS limb-scan & $2-7$ & 10 & 8 & $\sqrt{ }$ & $\sqrt{ }$ & 0.3 & Fig. $14 b$ \\
\hline Frequent cloud & $4-7$ & 10 & 8 & $\sqrt{ }$ & $\sqrt{ }$ & 0.3 & Fig. 15 \\
\hline
\end{tabular}

ozone absorption, and scattering of light by clouds. The surface reflection is assumed to be Lambertian and the ground albedo is set to $0.1,0.3,0.5$, and 0.9 . As only the cloud effect on the ozone profile retrieval will be focused on here, no aerosols are taken into account. The vertical profiles of pressure, temperature and ozone number density were taken from Prather and Remsberg (1993).

In the Earth's atmosphere, clouds occur in three different thermodynamic states: water, ice, and mixed states. Unlike the water clouds, the microphysical properties of the ice clouds cannot be characterized by a single shape and particlesize distribution, because the size, shape, orientation and internal structure of the ice particles in crystalline clouds can be very different (e.g., Kokhanovsky, 2004). Fortunately, our preliminary investigations have shown that the ozone profile retrieval is mainly affected by the cloud optical thickness rather than by the thermodynamic state of the cloud. Therefore, only water clouds are considered here. Furthermore, the cloud droplets are assumed to be spherical and Mie calculations are used to establish the scattering phase functions and scattering coefficients. The clouds are considered to be homogeneous.

The classification of water clouds in this study is based on the definitions of the International Satellite Cloud Climatology Project (ISCCP) and depends on the cloud optical thickness and cloud top pressure (Rossow and Schiffer, 1999). In this paper, the cloud top pressure is converted to the cloud top height using the pressure profiles mentioned above. For simplicity reasons, the top and bottom heights resulting from this transformation for each cloud type were shifted up- and downwards, respectively, to match the internal altitude grid levels of the forward model. As a result, in the cloud classification used throughout this study, shown in Table 2, the clouds of different types overlap in altitude, which is not the case in the original ISCCP classification. However, for our study, there are no disadvantages associated with this overlap.

Table 2 provides an overview of the sets of cloud parameters used for each considered cloud scenario. The following abbreviations are used in the table and in the text below: $\tau$ is the cloud optical thickness, $r_{e}$ denotes the effective radius of water droplets, A is used for the Lambertian surface albedo, and the viewing geometry is defined by the solar zenith angle (SZA) and the solar azimuth angle (SAA). The angles are defined at the tangent point.

\section{Absolute radiance vs. Chappuis triplet}

In this section, we employ the approximate relationships for the retrieval error obtained in Sect. 5 to analyze how the combination of the limb radiances in the Chappuis triplet affects the sensitivity of the ozone profile retrievals to tropospheric clouds. Furthermore, the validity of the linearity assumption employed to separate the contributions of the atmospheric absorbers and the reflection of the solar light by the clouds, see Eq. (22), is investigated. 

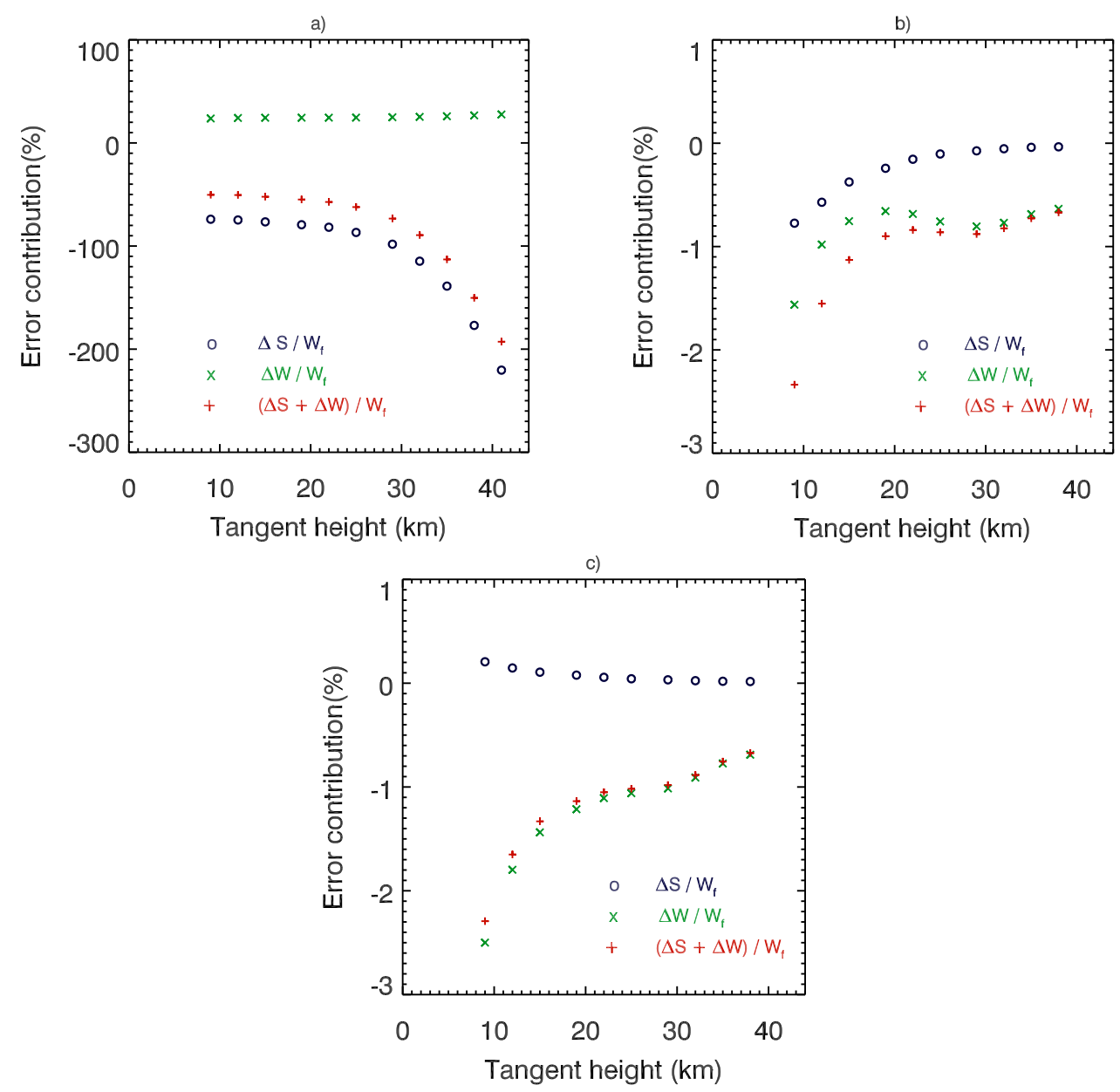

Fig. 2. Contribution of the terms $\Delta S\left(h_{i} ; 0\right) / W_{f}\left(h_{i}\right)$ and $\Delta W\left(h_{i}\right) / W_{f}\left(h_{i}\right)$ to the linearized approximate retrieval error obtained according to Eq. (22). Panel (a) shows the results for the absolute limb radiance at $602 \mathrm{~nm}$, panel (b) for the normalized limb radiance at $602 \mathrm{~nm}$ and panel (c) for the Chappuis triplet. The calculations were performed by following the scenario as given in Table 2.

As seen from Eq. (22), the magnitude and sign of the retrieval error depends on the relationship between the terms $\Delta S\left(h_{i} ; 0\right)$ and $\Delta W\left(h_{i}\right)$ which can be significantly different for the absolute limb radiance and for the Chappuis triplet. This is illustrated in Fig. 2. The upper left and right panels of the figure show the contributions of the scattering term $\Delta S\left(h_{i} ; 0\right) / W_{f}\left(h_{i}\right)$ and absorption term $\Delta W\left(h_{i}\right) / W_{f}\left(h_{i}\right)$ to the total retrieval error for the absolute and normalized limb radiance at $602 \mathrm{~nm}$, respectively, whereas the lower panel shows the same for the Chappuis triplet. The calculations were performed for the parameter set given in Table 2. It follows that for the absolute limb radiance, as shown in the upper left panel of Fig. 2, the contribution of the absorption term is positive whereas the contribution of scattering term is negative and dominates. The obtained results can be easily explained. On the one hand, the appearance of a cloud in the atmosphere usually leads to an increase of the reflected limb radiance as compared to the cloud-free case and, hence, to the positive value of $\Delta S\left(h_{i} ; 0\right)$. The only way for the cloud-free model to match the enhanced limb radiance is to decrease the ozone concentration. This results in the negative ozone retrieval error for the scattering term. On the other hand, the presence of a cloud leads to increased absorption and, therefore, to a decreased limb radiance. In this case, the absorption error term is positive because the cloud-free model needs larger ozone concentrations to match the increased path-absorption. Thus, in the case of the absolute limb radiance, the enhanced reflection of the solar light in a cloudy atmosphere is the main source of error in the retrieved ozone profile, occurring due to neglecting tropospheric clouds in the retrieval process.

On the contrary, the contribution of the scattering term is significantly smaller for the normalized limb radiance and for the Chappuis triplet, as shown in the upper right and in the lower panel of Fig. 2. In these cases, the error in the retrieved ozone profiles is mainly due to the differences in the gaseous absorption associated with changes in photon path lengths in a cloudy atmosphere. Comparing the contribution of the 
a)

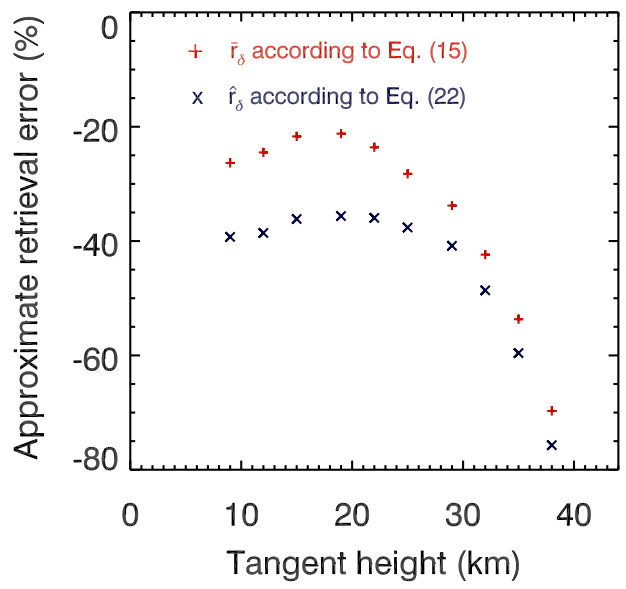

b)

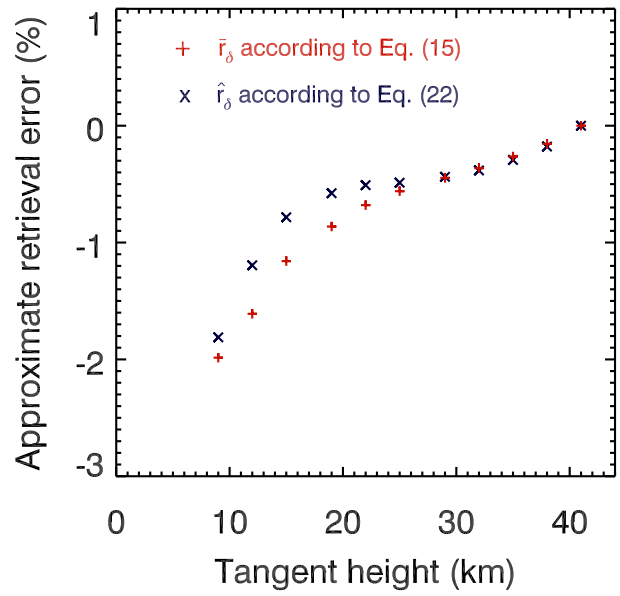

c)

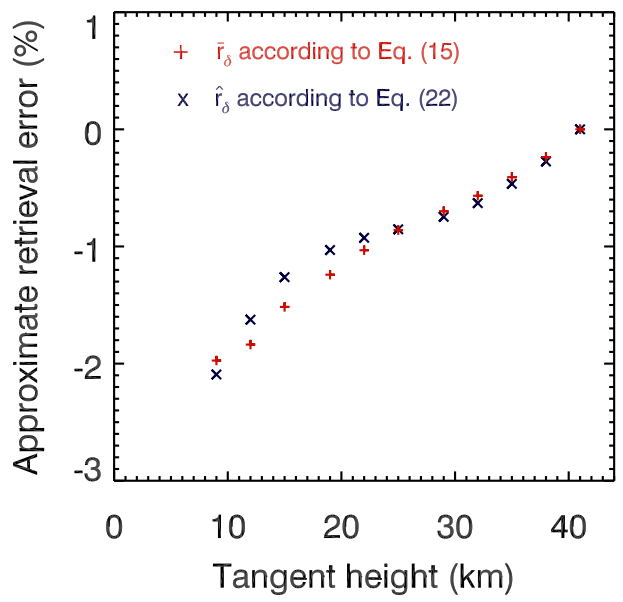

Fig. 3. Comparison of the approximate errors of the ozone profile retrieval calculated with and without linearity assumption according to Eqs. (22) and (15), respectively. Panel (a) shows the results for the absolute limb radiance at $602 \mathrm{~nm}$, panel (b) for the absolute normalized limb radiance at $602 \mathrm{~nm}$, and panel (c) for the Chappuis triplet. The calculations were performed for the same set of parameters as in Fig. 2.

absorption term to the ozone retrieval error in the case of the absolute and normalized limb radiance shown in the upper left and upper right panels of Fig. 2, respectively, one can see that this term changes its sign. This can be explained by the fact that, although in the presence of a cloud, the limb radiance decreases due to an enhancement of path-absorption at all relevant tangent heights, the relative decrease at the reference tangent height is stronger. Therefore, in the presence of a cloud, the normalised limb radiance increases due to additional path-absorption as compared to a cloud-free atmosphere. Thus, the cloud-free model needs less ozone to match the increased normalised limb radiance and the corresponding ozone retrieval error becomes negative.
As can be clearly seen, the impact of clouds is much larger for the absolute limb radiance as compared to the normalized one, and compared to the Chappuis triplet. Moreover, employing the normalized limb radiance or the Chappuis triplet in the framework of cloud-free model, one can expect a systematic underestimation of the retrieved ozone profile.

Figures 3 and 4 illustrate the impact of the linearity assumption used to derive the linearized representation for the approximate retrieval error as given by Eq. (22). The results are shown for the absolute limb radiance at $602 \mathrm{~nm}$ (panel a), the normalized limb radiance at $602 \mathrm{~nm}$ (panel b), and for the Chappuis triplet (panel c) for different values of surface albedo. Figure 3 shows the approximate error of the ozone profile retrieval calculated with and without linearity assumption according to Eqs. (22) and (15), respectively, for a surface albedo of 0.3 and the same cloud parameters and viewing geometry as described above. Figure 4 shows the 
a)

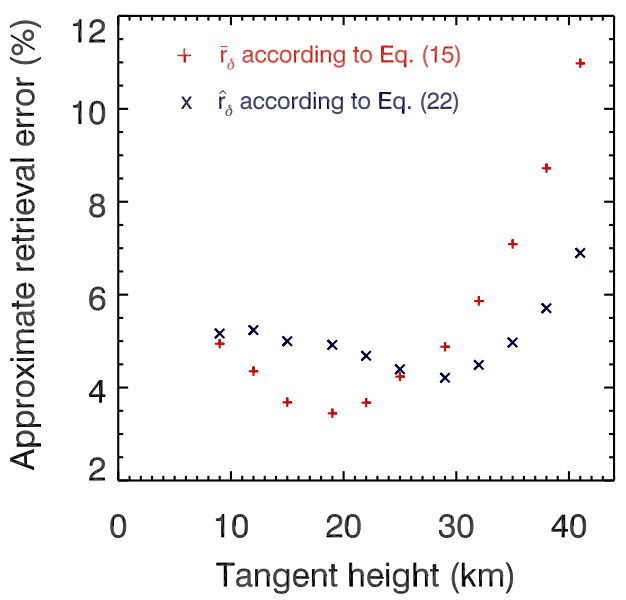

b)

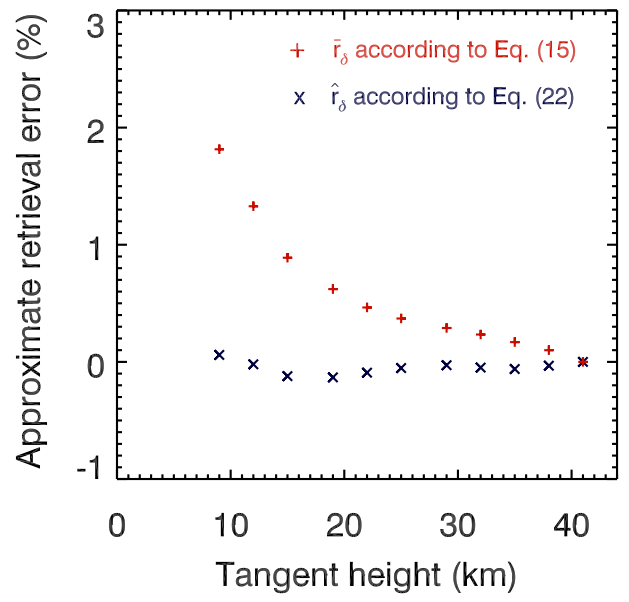

c)

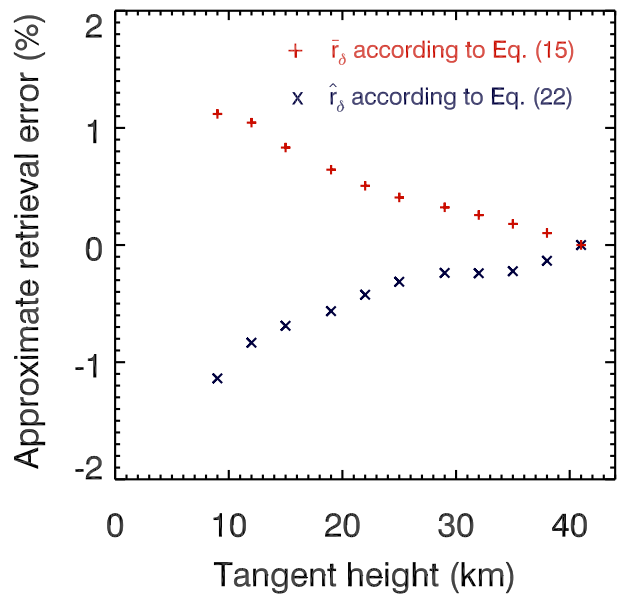

Fig. 4. Same as Fig. 3 but for a surface albedo of 0.9 .

same errors but for a surface albedo of 0.9. As seen from the plots, under certain conditions (e.g., high surface albedo) the linearization error for the Chappuis triplet is so high that not even the correct sign of the approximate error is reproduced.

The obtained results demonstrate that using the combination of the limb radiances in the Chappuis triplet leads to a significant decrease of the cloud impact on the retrieval process. On the other hand, this combination can increase the nonlinearity of the problem making the linear representation for the approximate error as given by Eq. (22) unusable. Therefore, this representation is not used in the discussion below. Instead, the dependence of the retrieval error on the cloud parameters is discussed in the next section employing the much more robust expression for the approximate error as given by Eq. (15).

\section{Investigation of the retrieval errors}

In this section, the errors in the retrieved vertical distributions of ozone occurring due to neglecting tropospheric clouds in the retrieval process are analyzed employing the full endto-end numerical approach for different cloud scenarios and viewing geometries. The obtained results are explained using the approximate representation of the retrieval error obtained above (see Eq. 15).

An example of the ozone vertical profile obtained neglecting tropospheric clouds in the retrieval process, as described by Eq. (8), is shown in Fig. 5 in comparison with the true vertical distribution of ozone. The cloud parameters and the observation geometry are the same as in Fig. 2. As the plot shows, the effect of the tropospheric clouds appears as a small underestimation of the ozone number density in the altitude region below $30 \mathrm{~km}$ whereas in the upper layers, where most of the information originates from the UV wavelengths, the ozone retrieval is relatively insensitive to clouds. As 


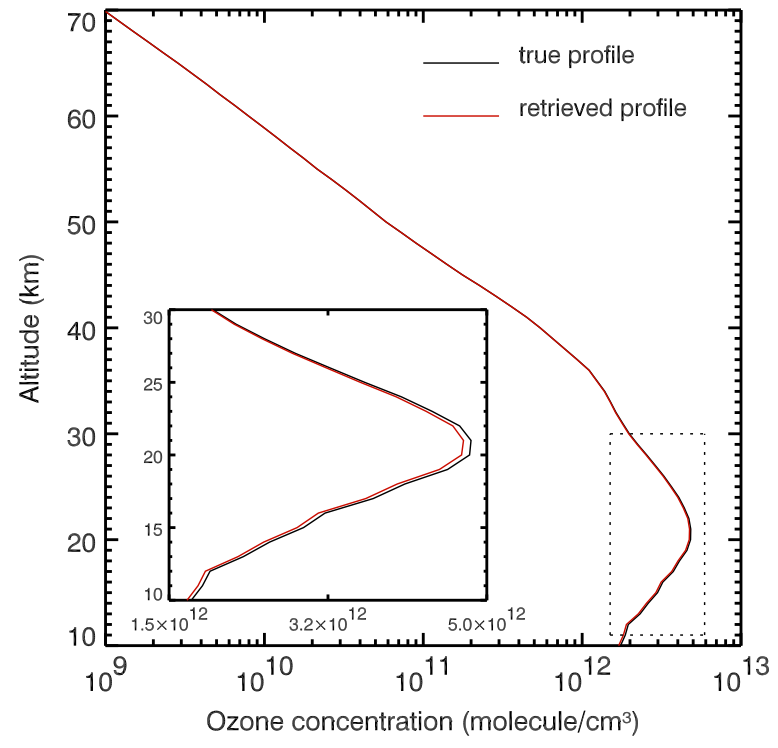

Fig. 5. An example of the ozone vertical profile obtained neglecting the tropospheric clouds in the retrieval process, as described by Eq. (8), in comparison with the true vertical distribution of ozone. The calculations were performed for the same set of parameters as in Fig. 2.

shown below, this low bias in the retrieved ozone concentrations at lower altitudes is typical for neglecting tropospheric clouds in the retrieval process for most cloud scenarios.

\subsection{Cloud optical thickness}

Figure 6 shows the sensitivity of ozone profile retrievals to tropospheric clouds for different $\tau$ and different altitudes of the cloud layer. The SZA and SAA are set to $30^{\circ}$ and $90^{\circ}$, respectively. The sensitivity is expressed in terms of the relative percentage error according to Eq. (10). Panels (a) and (b) of Fig. 6 show the retrieval errors for the low and middle clouds, respectively, according to the classification given in Table 2. As seen from the plot, when being neglected in the retrieval process, low and middle clouds with the same $\tau$ cause similar errors in the retrieved ozone profiles. Generally, the retrieval error caused by this type of clouds is up to about $5 \%$ at $10 \mathrm{~km}$ altitude decreasing with increasing altitude and with decreasing $\tau$. The results for the high clouds are shown in panels (c) and (d) of Fig. 6. Panel (c) shows the results for the standard tangent height range, as given in Table 1, where the cloud is in the instrument field of view. Panel (d) shows the results for the lowest tangent height set to $19 \mathrm{~km}$. As an investigation of the retrieval error within the cloud is outside the scope of this study, the results for high clouds are shown only for the altitudes above the cloud layer, i.e., above $18 \mathrm{~km}$. As clearly seen from the plots, the retrieval error reaching $17 \%$ at $18 \mathrm{~km}$ for the standard tangent height range $\left(h_{\text {low }}=9 \mathrm{~km}\right)$ decreases to less than $3.5 \%$ if the lines of sight are rejected, for which the cloud is in the field of view of the instrument $\left(h_{\mathrm{low}}=19 \mathrm{~km}\right)$. In future versions of the ozone profile retrieval from SCIAMACHY limb measurements cloud top height information - also retrieved from SCIAMACHY limb observations with a colour-index approach similar to the PSC detection described in von Savigny et al. (2005b) - will be employed to limit the range of tangent heights used.

For all cloud layer altitudes, the retrieval errors shown in Fig. 6 are mostly negative and decrease with increasing altitude as well as with decreasing $\tau$. Thus, most typically, the ozone concentrations are underestimated if the tropospheric clouds are neglected in the retrieval process. However, for a small $\tau$, the retrieval error can change its sign and become positive, as for example, for low and middle clouds at $\tau=1$. These general dependencies can be explained considering the approximate retrieval error as given by Eq. (15).

Panel (a) of Fig. 7 shows the approximate retrieval error at different tangent heights calculated for a middle cloud (as in Fig. 6b). As can be seen from the plots, the approximate retrieval errors shown in Fig. 7a are in good qualitative agreement with the errors obtained using the full end-to-end numerical approach presented in Fig. 6b. In particular, the retrieval errors in both Figs. $6 \mathrm{~b}$ and $7 \mathrm{a}$ change the sign between $\tau=1$ and $\tau=2$ and increase with growing optical thickness of the cloud for $\tau \geq 2$. As, according to Eq. (15), the approximate retrieval error is proportional to the difference in the limb signals for a cloudy and a cloud-free atmosphere, the dependence of the retrieval error on the cloud optical thickness can be analyzed considering the corresponding values of the Chappuis triplet. Panels (b) and (c) of Fig. 7 show the Chappuis triplet for a cloudy atmosphere (for the same scenario as in Fig. 6b) as a function of the $\tau$ as well as the Chappuis triplet and the integrated weighting function for a cloud-free atmosphere at $12 \mathrm{~km}$ and $29 \mathrm{~km}$ tangent height, respectively. Obviously, the Chappuis triplet in a cloudy atmosphere, $y_{c}$, increases with increasing $\tau$. Consistently with Fig. 7a, the Chappuis triplet value for a cloudy atmosphere at $\tau=1$ is smaller than the cloud-free value leading to a positive retrieval error (note that the integrated weighting function is negative) whereas the opposite behaviour is observed for $\tau \geq 2$.

The dependence of the ozone retrieval errors on the optical depth of tropospheric clouds, discussed above, can be explained using the findings of Roebeling et al. (2005) and Liou (1973) who have discovered that the reflected solar radiation at visible wavelengths $(630 \mathrm{~nm}$ and $700 \mathrm{~nm}$, respectively) increases with increasing $\tau$, i.e., optically thicker clouds reflect more solar light. As demonstrated in Appendix A, a variation of cloud parameters causing an increase in the reflected solar radiation also leads to an increase in the Chappuis triplet values. Thus, the enhanced reflection due to optically thick clouds causes an increase in limb radiance leading, in turn, to larger values of the Chappuis triplet, which results then in smaller ozone concentrations when retrieving the profiles neglecting the clouds. Clearly, optically thicker 
a)

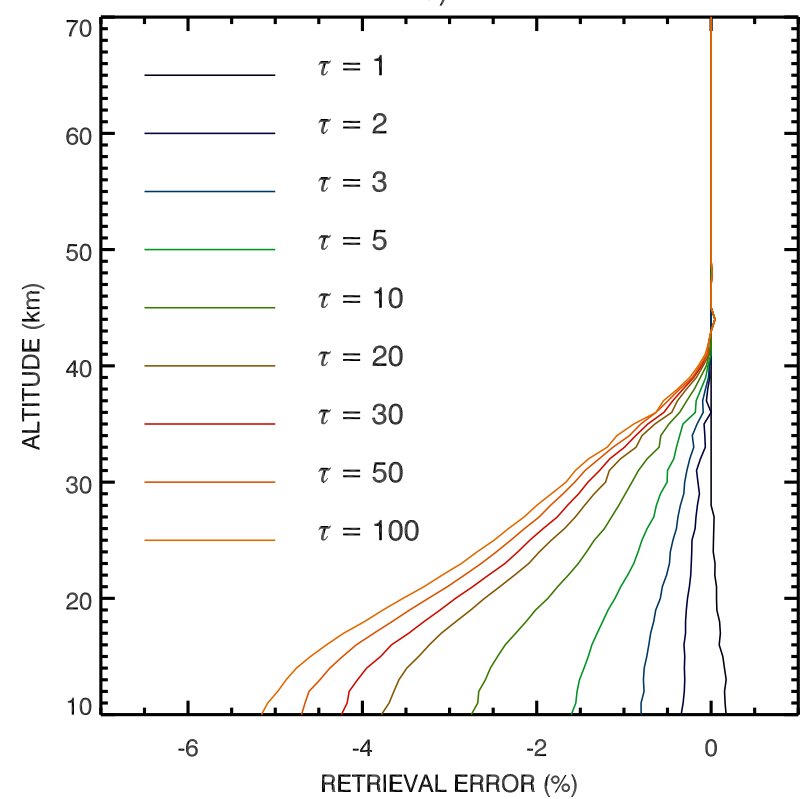

C)

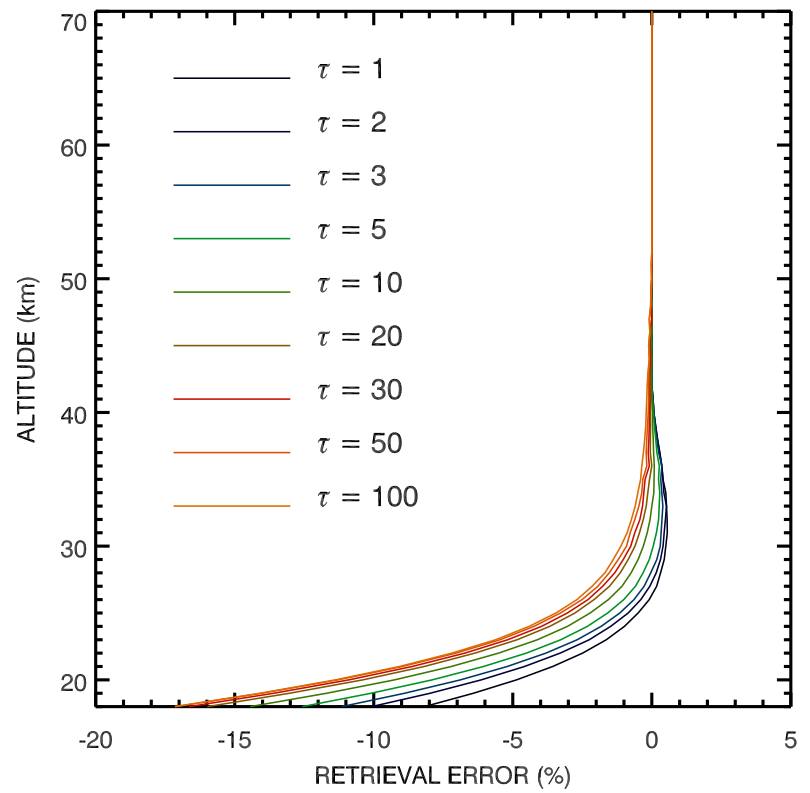

b)

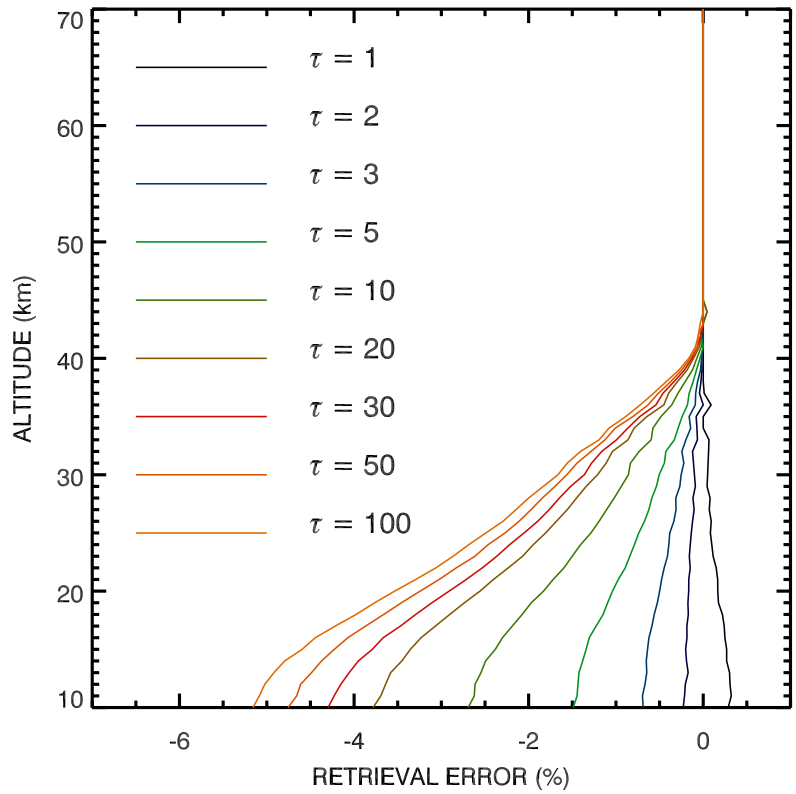

d)

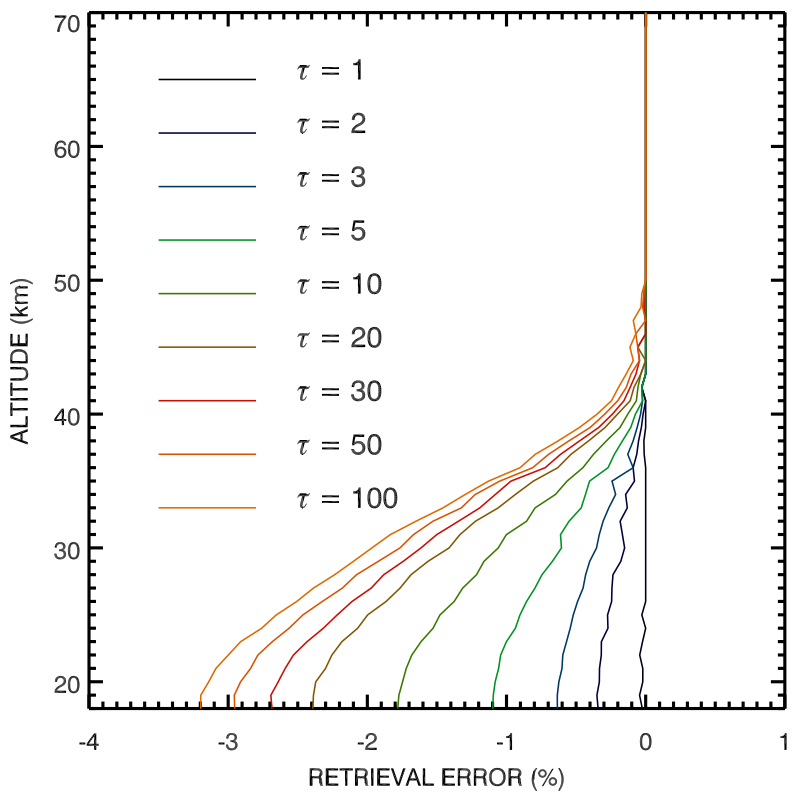

Fig. 6. Relative errors in the retrieved ozone profiles due to neglect of clouds in the retrieval process. Results are shown for different altitudes of the cloud layer and for different cloud optical thicknesses $\tau$ : (a) low clouds (1-3 km), (b) middle clouds (2-7 km), (c) high clouds (6$15 \mathrm{~km}$ ) for the standard tangent height range, i.e., $h_{\text {low }}=9 \mathrm{~km}$ is the lowest tangent height included in the retrieval, (d) high clouds for the reduced tangent height range, $h_{\text {low }}=19 \mathrm{~km}$.

clouds reflecting more solar light affect the retrievals more strongly. This provides an explanation for the typical dependence of ozone profile retrieval errors on $\tau$ and the general underestimation of ozone concentrations retrieved from limb-scatter observations neglecting tropospheric clouds in the retrieval process.

\subsection{Effective radius of water droplets}

In this section, the dependence of the ozone profile retrieval error on the effective radius of water droplets within the cloud is investigated. The effective radius of water droplets, $r_{e}$, is defined as the ratio of the third moment to the second moment of the droplet size distribution (Hansen and Travis, 1974). The comparison is performed for a middle cloud and 

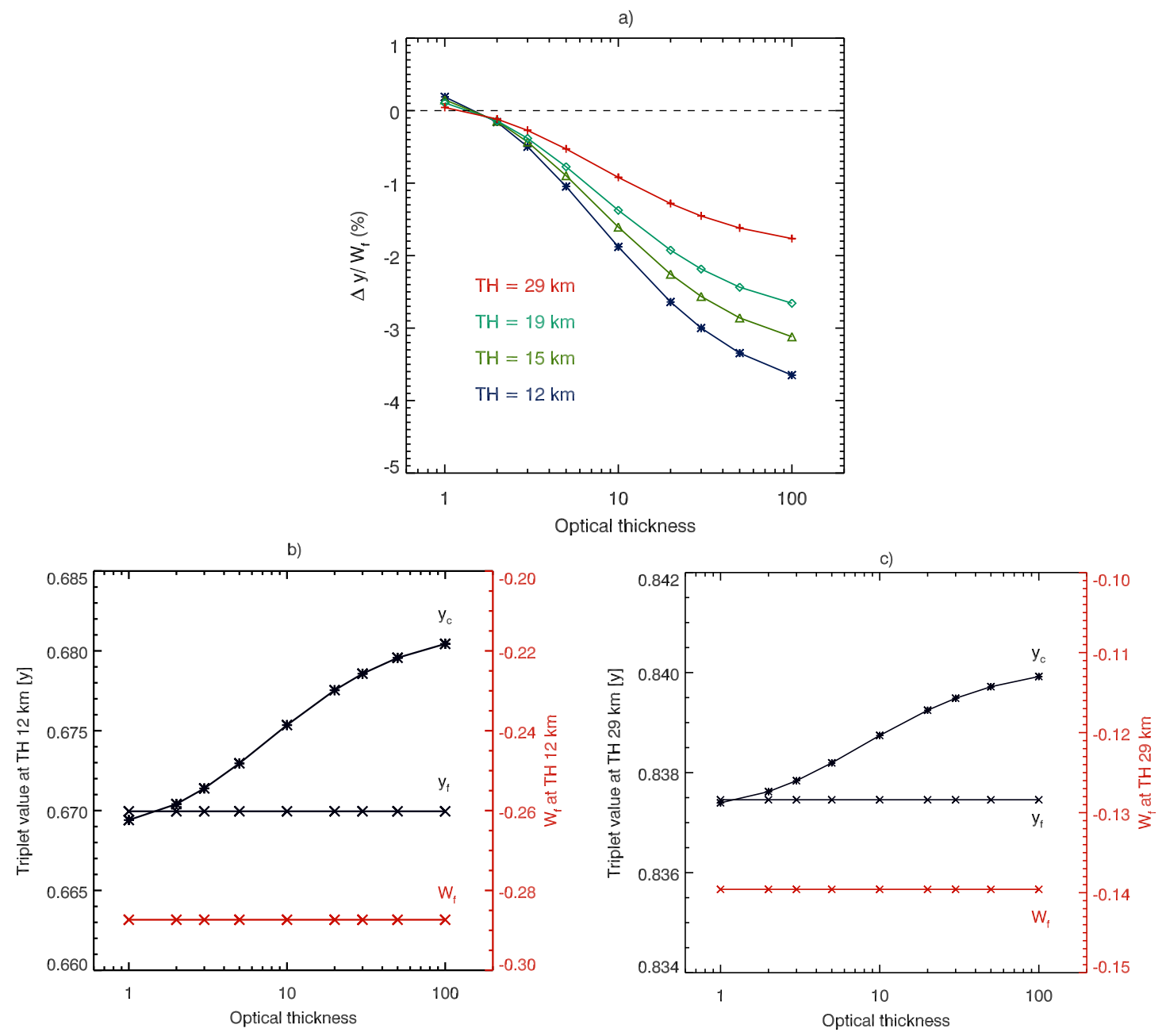

Fig. 7. Panel (a) approximate retrieval error according to Eq. (15) at tangent heights of $12 \mathrm{~km}, 15 \mathrm{~km}, 19 \mathrm{~km}$ and $29 \mathrm{~km}$ as a function of the cloud optical thickness. Panels (b) and (c) Chappuis triplet for a cloudy and a cloud-free atmosphere as well as integrated weighting function at a tangent height of $12 \mathrm{~km}$ and $29 \mathrm{~km}$, respectively. The calculations were performed for a middle cloud (the same scenario as in Fig. $6 \mathrm{~b}$ ). Please note that the subscripts "c" and "f" refer to a cloudy and a cloud-free atmosphere, respectively.

the parameter set given in Table 2. Since the $\tau$ is fixed, the water droplet scattering phase function is the only parameter changing when the $r_{e}$ is varied.

The sensitivity of the ozone vertical profile retrievals, performed neglecting tropospheric clouds, to the $r_{e}$ within the cloud is illustrated in panel (a) of Fig. 8. This figure demonstrates that the impact of clouds with small water droplets is slightly higher than for larger droplets. However, as the difference in the relative errors between the large $(20 \mu \mathrm{m})$ and small $(4 \mu \mathrm{m})$ water droplets is less than $0.5 \%$, one can conclude that the overall influence of the $r_{e}$ on the ozone profile retrieval is rather small. Similar to the previous section, this dependence can be qualitatively explained considering the approximate retrieval error as given by Eq. (15). Panel (b) of Fig. 8 shows the approximate retrieval error as a function of $r_{e}$ for three different tangent heights. It can be clearly seen, that the retrieval error decreases with increasing $r_{e}$ which is in line with the results presented in Fig. 8a. Panel (c) of Fig. 8 shows the Chappuis triplet for a cloudy atmosphere as a function of the $r_{e}$ as well as the Chappuis triplet and the integrated weighting function for a cloud-free atmosphere. As clearly seen, the Chappuis triplet for a cloudy atmosphere decreases with increasing $r_{e}$ getting closer to cloud-free values which results in smaller retrieval errors.

As shown by e.g., Kokhanovsky (2001), clouds having smaller water droplet effective radii reflect more solar radiation as compared to clouds consisting of larger water droplets if all other cloud parameters are identical. This can be explained by the fact that the scattering phase function of larger water droplets is peaked much more strongly in the forward direction as compared to the smaller droplets. Thus, the probability of the backward scattering (i.e., of the reflection) is lower for larger water droplets. As, according to our findings in Appendix A, for the typical atmospheric/observation 


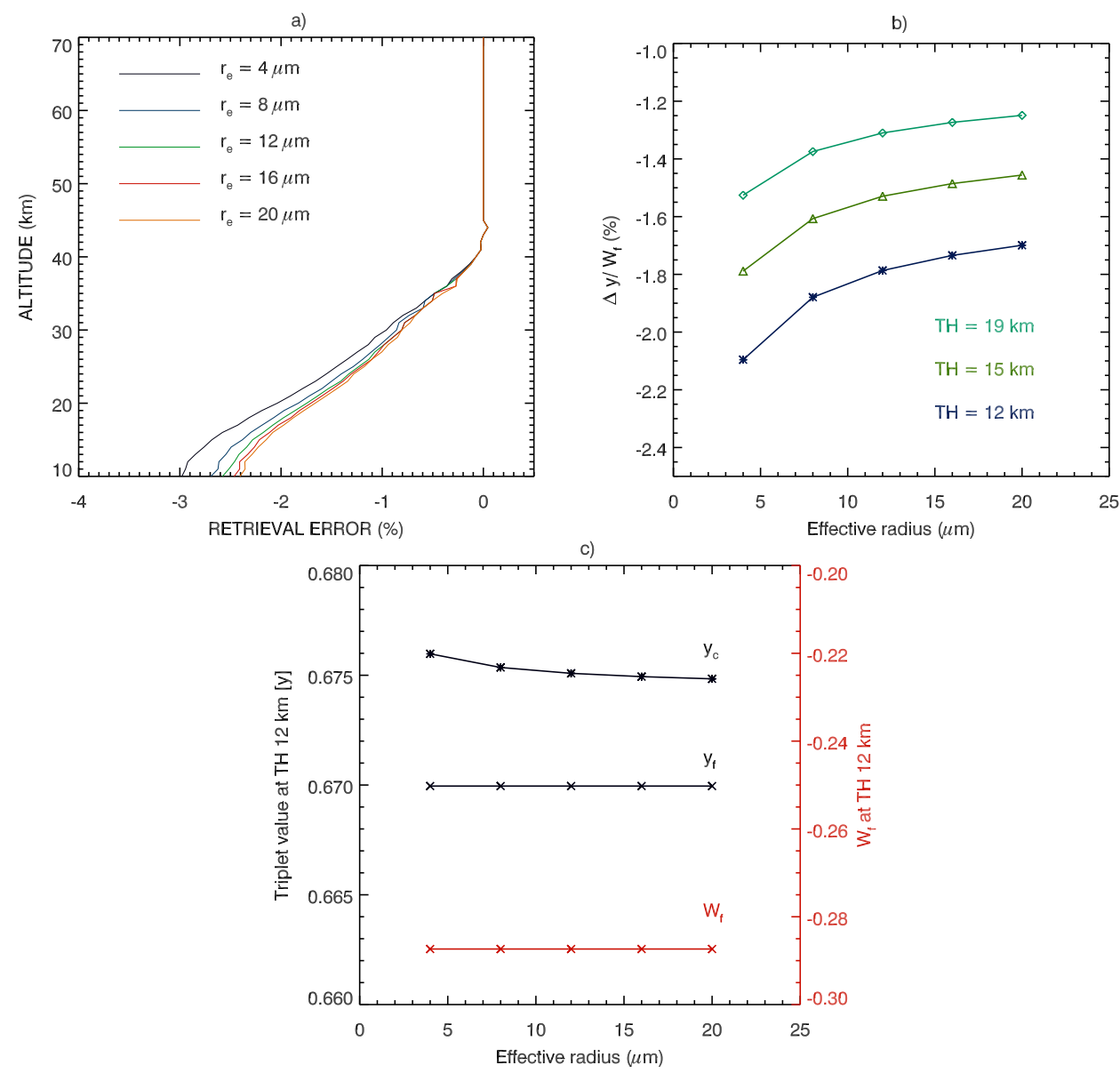

Fig. 8. Panel (a) relative errors in the retrieved ozone profiles due to neglect of clouds in the retrieval process for different $r_{e}$. Panel (b) approximate retrieval error according to Eq. (15) at tangent heights of $12 \mathrm{~km}, 15 \mathrm{~km}$, and $19 \mathrm{~km}$ as a function of the $r_{e}$. Panel (c) Chappuis triplet for a cloudy and a cloud-free atmosphere as well as integrated weighting function at a tangent height of $12 \mathrm{~km}$. The calculations were performed for a middle cloud and the parameter set given in Table 2.

conditions the Chappuis triplet has a similar behaviour as the reflected solar radiation, one can conclude that the results shown in Fig. 8 are in agreement with the finding of Kokhanovsky (2001). We note, however, that because of a different viewing geometry and a combination of the limb radiances into the Chappuis triplet, the impact of the $r_{e}$ observed in this study is much smaller compared to the results presented by Kokhanovsky (2001).

\subsection{Cloud top height and geometrical thickness}

Other cloud parameters that can affect the retrieval error include the geometrical thickness and cloud top height. As shown by Rozanov and Kokhanovsky (2008) (and references therein) these parameters play a major role when retrieving the vertical columns of ozone from the measurements of backscattered solar radiation in nadir viewing geometry. In this section, we analyze the impact of the cloud geometrical thickness and cloud top height on ozone vertical profiles retrieved from limb-scatter measurements. The calculations are performed for the parameter set given in Table 2 .

The left panel of Fig. 9 illustrates the ozone profile retrieval errors due to neglect of clouds in the retrieval process for different cloud top heights. The results are obtained for a fixed cloud geometrical thickness of $1 \mathrm{~km}$. As seen from the plot, the dependence of the retrieval error on the cloud top height is insignificant for cloud layers below $7 \mathrm{~km}$. Because of a finite field of view, the instrument directly observes the atmosphere down to about $7.5 \mathrm{~km}$ altitude at the lowest tangent height included in the retrieval $(9 \mathrm{~km})$. Thus, the reason for an increased dependence of the retrieval errors on cloud top height for the cloud layers above $7 \mathrm{~km}$ is that these clouds are already in the field of view of the instrument.

The right panel of Fig. 9 shows the ozone profile retrieval errors due to neglecting clouds in the retrieval process for different geometrical thicknesses of the cloud. In this comparison, the cloud top height is fixed to $7 \mathrm{~km}$. As clearly seen, in contrast to nadir observations considered by Rozanov and 
a)

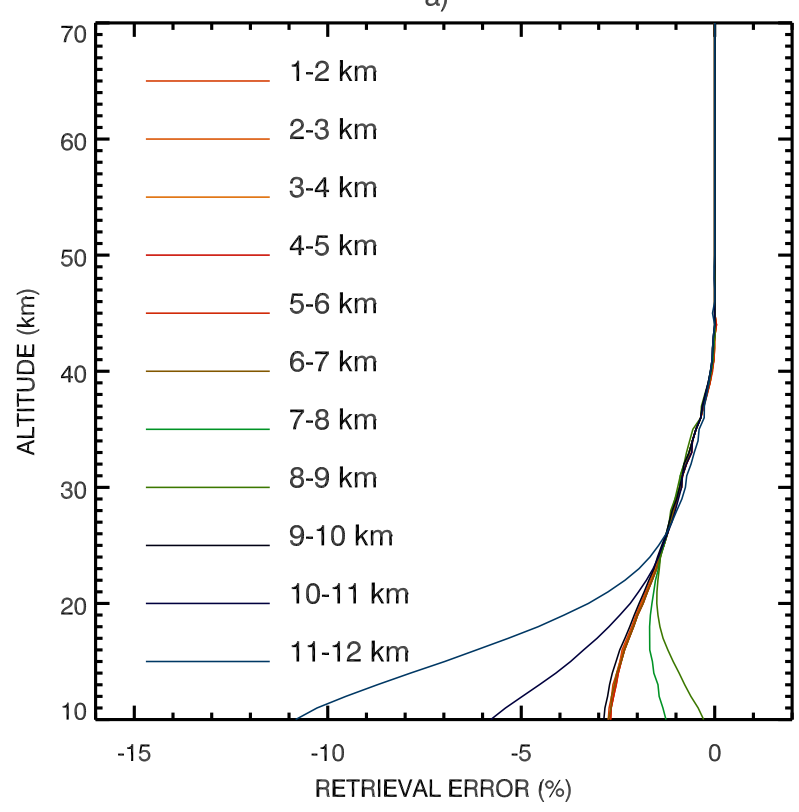

b)

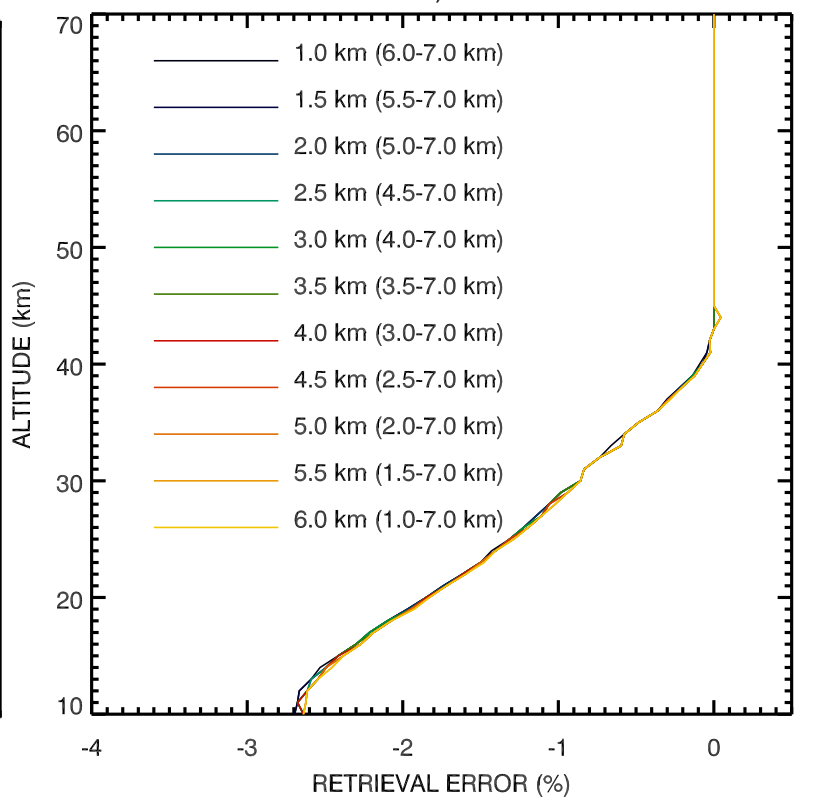

Fig. 9. Relative errors in the retrieved ozone profiles due to neglect of clouds in the retrieval process. The results are shown for different cloud top heights and geometrical thicknesses of the cloud. Left panel: different cloud top heights for a fixed cloud geometrical thickness $(1 \mathrm{~km})$. Right panel: different cloud geometrical thicknesses for a fixed cloud top height $(7 \mathrm{~km})$. The calculations were performed for the parameter set given in Table 2 .

Kokhanovsky (2008), the retrieval error for limb-scatter measurements is almost independent of the geometrical thickness of the cloud. Please note that the $\tau$ is fixed in this comparison, i.e., it does not change with a changing geometrical thickness of the cloud. The main reasons for the differences with respect to nadir observations are the combination of the limb radiances in the Chappuis triplet suppressing the overall impact of clouds.

\subsection{Ground albedo}

All results presented above are obtained assuming a constant surface albedo of 0.3 in both forward model and the retrieval algorithm. In this section, we investigate the influence of the surface albedo on the ozone vertical profiles retrieved neglecting the tropospheric clouds. For the first set of sensitivity studies presented in this section, the surface albedo is assumed to be known and the retrievals are performed using the correct values of the albedo, i.e., the surface albedo is the same when modelling the limb observations and retrieving the profiles. Later, we also discuss the effect of an incorrect surface albedo value on the ozone profile retrievals. The calculations are performed for a middle cloud with $\tau=10$, and the other parameters as given in Table 2.

The top left panel of Fig. 10 shows the relative error in the retrieved vertical distributions of ozone occurring for different surface albedo values when neglecting clouds in the retrieval process. As can be clearly seen, the impact of the surface albedo on the retrieval error is quite strong. In particular, the ozone concentrations are underestimated by up to $6.5 \%$ at $10 \mathrm{~km}$ altitude when neglecting clouds over dark surfaces $(\mathrm{A} \sim 0.1)$ whereas over bright surfaces $(\mathrm{A} \sim 0.9)$ an overestimation by up to $1.5 \%$ at $10 \mathrm{~km}$ is observed. Similar to all previous results, the retrieval error decreases with increasing altitude. In the considered case, the largest retrieval errors occur over the dark surfaces and the smallest effect is observed for a surface albedo of 0.5 .

Similar to previous discussions, the obtained results can be explained considering the approximate retrieval error as given by Eq. (15). The top right panel of Fig. 10 shows the approximate retrieval error as a function of surface albedo for four different tangent heights. We observe that the approximate error shows the same behaviour as the retrieval errors resulting from the full end-to-end numerical approach shown in the top left panel of the figure. Looking at Eq. (15), it is obvious that the behaviour of the retrieval error can be analyzed considering the limb signals for a cloudy and a cloud-free atmosphere. The middle panels of Fig. 10 show the Chappuis triplet for a cloudy and a cloud-free atmosphere as well as the integrated weighting function for a cloud-free atmosphere as functions of surface albedo for a tangent height of $12 \mathrm{~km}$ (left middle panel) and $29 \mathrm{~km}$ (right middle panel). It can be clearly seen, that both the Chappuis triplet for a cloudy and a cloud-free atmosphere increase with increasing surface albedo. However, the dependence for cloud free conditions is stronger. As, according to our findings in Appendix A, for 

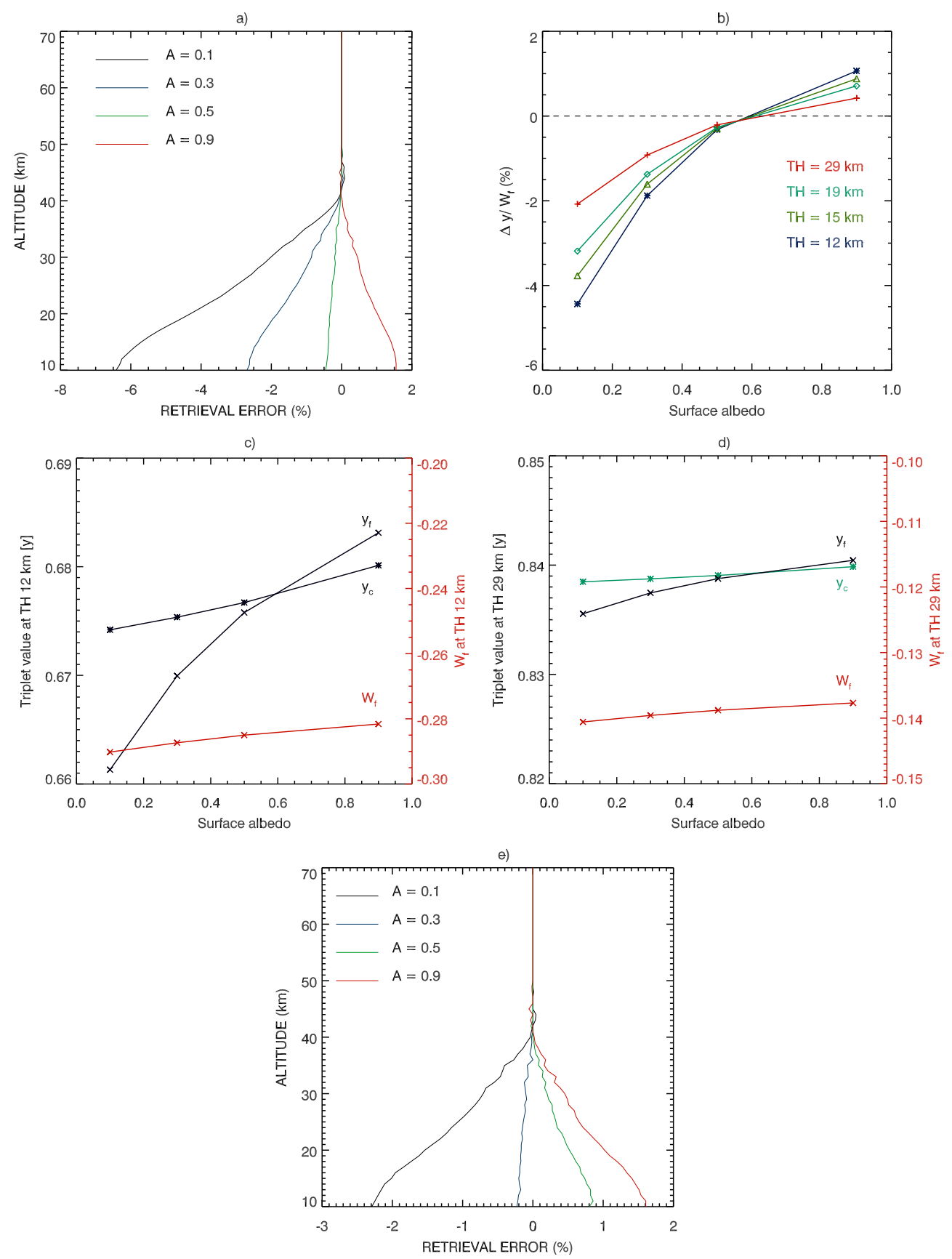

Fig. 10. Left top panel: relative errors in the retrieved ozone profiles due to neglect of clouds in the retrieval process for different surface albedos. Right top panel: approximate retrieval error according to Eq. (15) at tangent heights of $12 \mathrm{~km}, 15 \mathrm{~km}, 19 \mathrm{~km}$ and $29 \mathrm{~km}$ as a function of the surface albedo. Middle panels: Chappuis triplet for a cloudy and a cloud-free atmosphere as well as integrated weighting function at a tangent height of $12 \mathrm{~km}$ and $29 \mathrm{~km}$, respectively. The calculations were performed for a middle cloud, $\tau=10$, and the parameter set given in Table 2. Bottom panel: same as the left top panel but $\tau$ of 2 .

the typical atmospheric/observation conditions the Chappuis triplet has a similar behaviour as the reflected solar radiation, it is clear that it should increase with increasing surface albedo because more solar light is reflected and this increase should be smaller for a cloudy atmosphere because the surface is partially screened by the cloud.
For the case under consideration, $y_{f}<y_{c}$ for low surface albedo leading to negative retrieval errors whereas $y_{f}>y_{c}$ for high surface albedo resulting in positive retrieval errors (note that the integrated weighting function is negative). Thus, there is an albedo value at which the Chappuis triplets for a cloudy and a cloud-free atmosphere are equal and vertical 

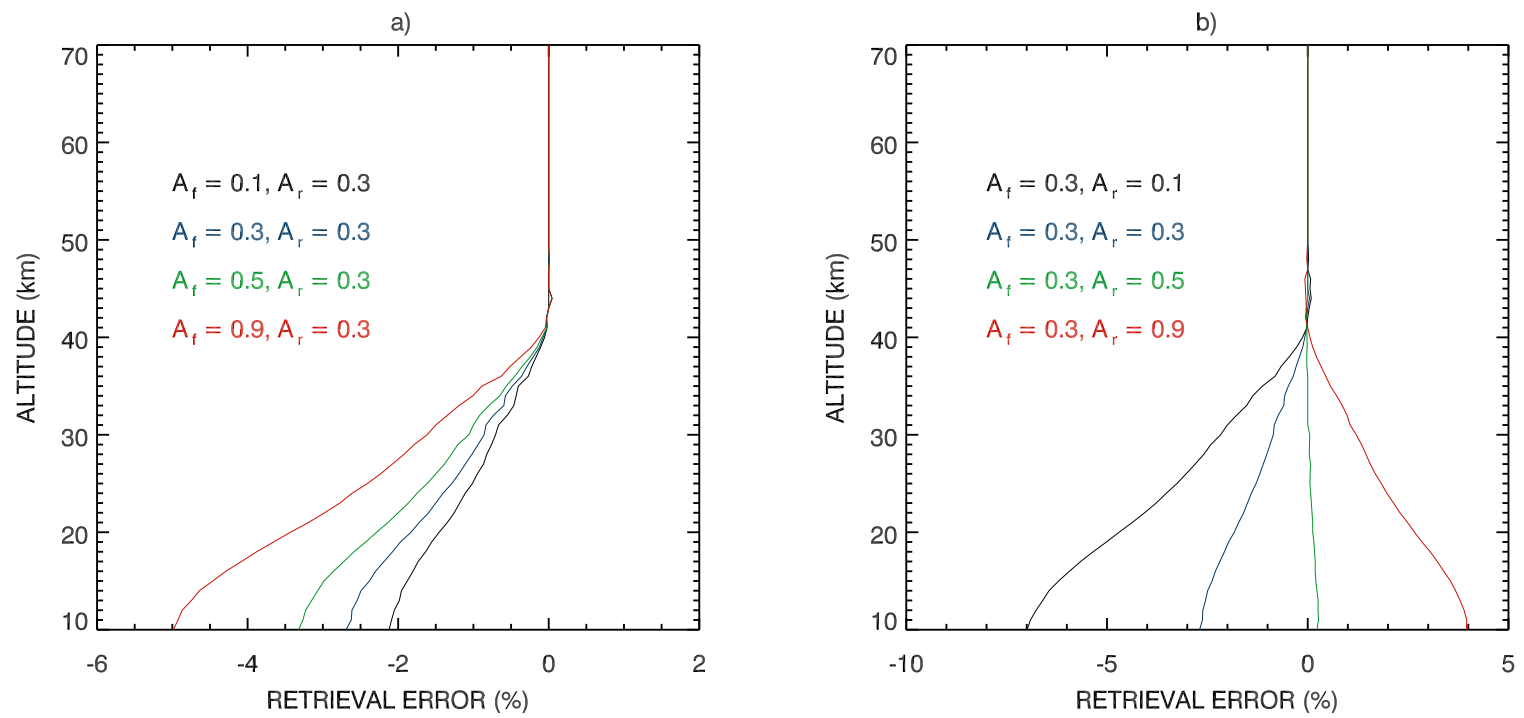

Fig. 11. Relative ozone profile retrieval errors for different surface albedo values $\mathrm{A}_{f}$ in the forward simulations, but a fixed albedo $\mathrm{A}_{r}=0.3$ assumed in the retrievals (panel a), and a constant albedo of $\mathrm{A}_{f}=0.3$ in the forward simulations and varying albedo $\mathrm{A}_{r}$ used for the retrievals (panel b). The calculations were performed for the parameter set given in Table 2.

profiles of ozone are retrieved without any error. However, the Chappuis triplet for a cloudy atmosphere, $y_{c}$, depends not only on the surface albedo but also on the $\tau$ (see Fig. 7). Therefore, the curves representing $y_{c}$ in Figs. 10c and 10d will be shifted upwards or downwards for clouds having $\tau$ greater or less than 10, respectively. The bottom panel of Fig. 10 shows the relative retrieval errors for different surface albedos and the same parameters as in the top left panel, except that the $\tau$ is 2 . The maximum errors are lower than for a $\tau$ of 10 . This panel clearly shows that the albedo leading to essentially zero retrieval errors is smaller than for $\tau=10$, in agreement with the dependencies shown in the two middle panels of Fig. 10.

Taking into account that the Chappuis triplet for a cloudfree atmosphere, $y_{f}$, is independent of $\tau$, one can conclude that the surface albedo value where $y_{f} \approx y_{c}$ (and the retrieval is done error-free) depends on $\tau$. This consideration shows that the retrieval error caused by neglecting clouds can be decreased by including an effective surface albedo in the retrieval process. We note, that the mitigation of the impact of clouds on the ozone profile retrievals by fitting an effective ground albedo has been considered in e.g., Rault (2004) and Roth et al. (2007).

Now we discuss several cases where the actual surface albedo value is not exactly known, unlike the studies discussed earlier in this section. Panel (a) of Fig. 11 shows ozone profile retrieval errors assuming different albedo values in the forward simulation and an albedo of $\mathrm{A}_{r}=0.3$ for the retrievals. Panel (b) of the same figure shows the obtained retrieval errors based on a fixed surface albedo of $\mathrm{A}_{f}=0.3$ in the forward simulation of the synthetic observations, and different values for the surface albedo in the cloud-free retrieval.
We note that the retrieval errors in panel (b) of Fig. 11 are very similar to the errors shown in the left panel of Fig. 10 for the same values of the albedo assumed in the retrievals. This finding is easily explained by panels (c) and (d) of Fig. 10 showing that the Chappuis triplet $\mathrm{y}_{c}$ for the cloudy case is only weakly dependent on surface albedo, whereas the triplet for the cloud-free case $\mathrm{y}_{f}$ shows a much stronger dependence. In other words, under cloudy conditions the effect of surface albedo on the Chappuis triplet is rather small compared to a cloud-free scenario. The ozone profile retrieval errors depend more strongly on the albedo value assumed in the cloud-free retrievals. This also explains why the differences in retrieval errors between the different cases shown in panel (a) of Fig. 11 are smaller than in panel (b). Finally, we note that the relative differences between the cases shown in panels (a) and (b) of Fig. 11 are consistent with the dependence of the cloudy and cloud-free Chappuis triplet values shown in the panels (c) and (d) of Fig. 10, and can be qualitatively derived immediately from these panels.

It is also noteworthy that for typical measurements over land and ocean, the surface albedo is low and, thus, the retrieved ozone concentrations are generally underestimated if tropospheric clouds are not considered in the retrieval process (see Fig. 10a). This may be one of the reasons for the low bias observed in the vertical distributions of the stratospheric ozone retrieved from the OSIRIS limb-scatter observations when comparing to POAM III (von Savigny et al., 2005a) and ACE (Dupuy et al., 2009) solar occultation measurements. 

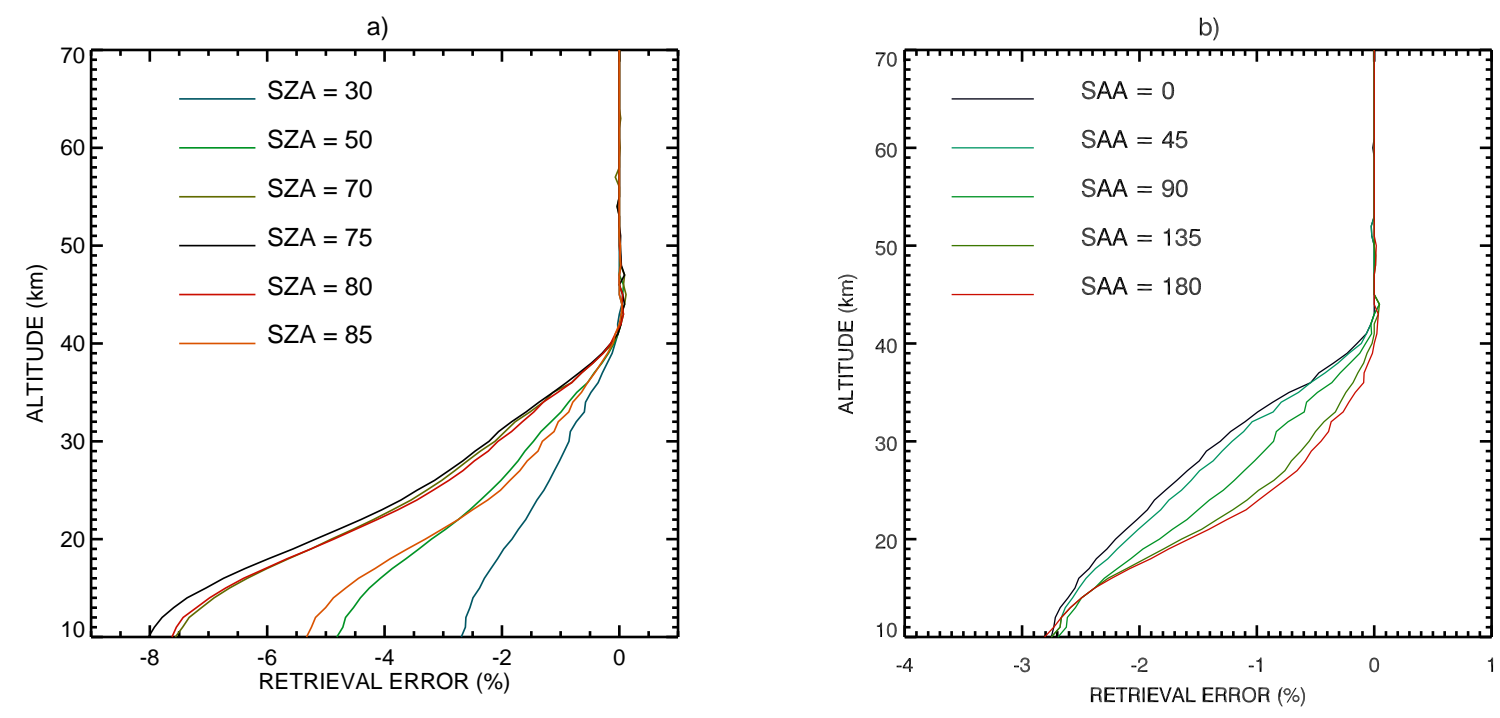

Fig. 12. Relative errors in the retrieved ozone profiles due to neglect of clouds in the retrieval process for different viewing geometries. Left panel: retrieval errors for different SZAs and a fixed SAA of $90^{\circ}$. Right panel: retrieval errors for different SAAs and a fixed SZA of $30^{\circ}$. The calculations were performed for the scenario as given in Table 2 .

a)

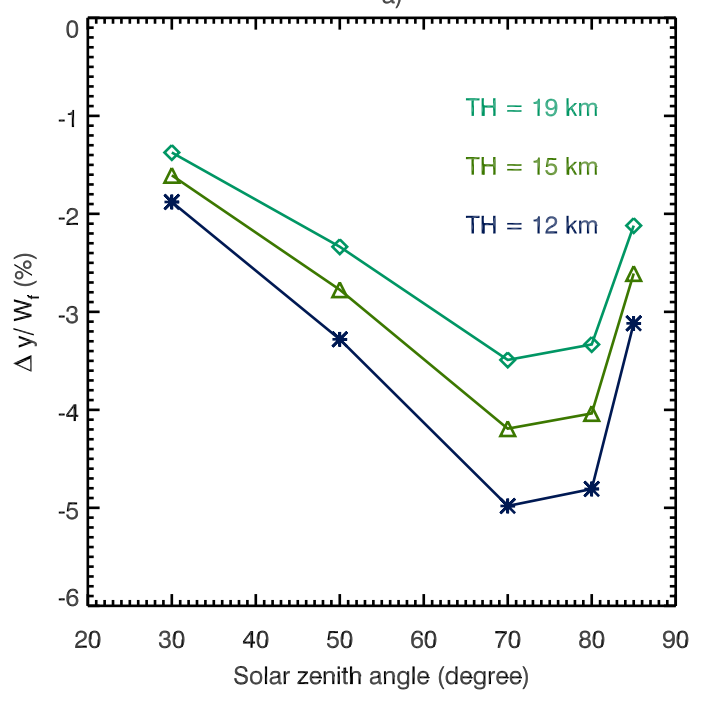

b)

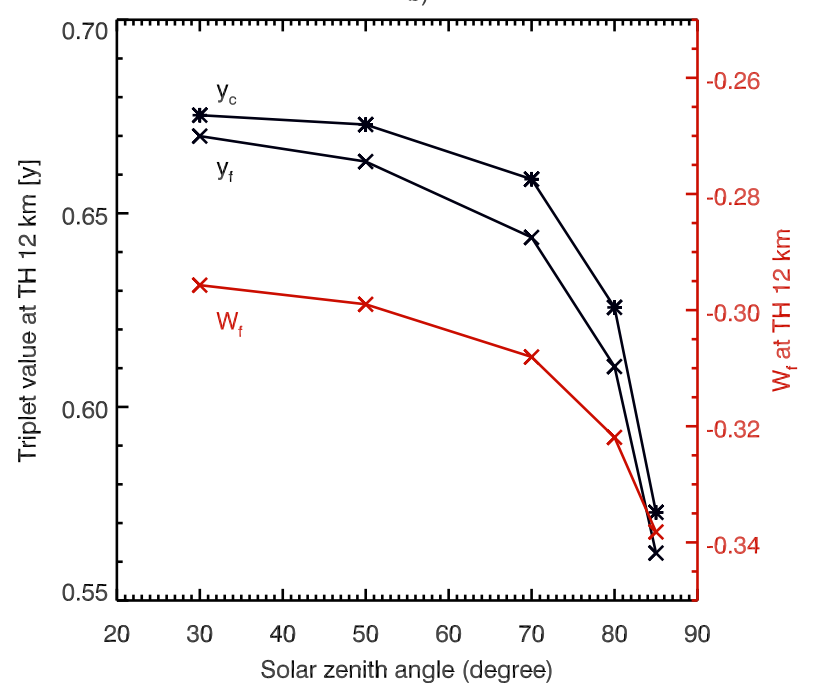

Fig. 13. Left panel: approximate retrieval error according to Eq. (15) at tangent heights of $12 \mathrm{~km}, 15 \mathrm{~km}$, and $19 \mathrm{~km}$ as a function of the SZA. Right panel: Chappuis triplet for a cloudy and a cloud-free atmosphere as well as integrated weighting function at a tangent height of $12 \mathrm{~km}$. The calculations were performed for a middle cloud (the same scenario as in Fig. 12).

\subsection{Solar zenith and azimuthal angles}

In this section, we discuss the influence of the viewing geometry, defined by the SZA and SAA, on the vertical distributions of ozone retrieved neglecting tropospheric clouds. Similar to previous investigations, all calculations are performed for the parameter set given in Table 2.

In Fig. 12, the relative errors in the retrieved ozone profiles for different SZAs and a fixed SAA of $90^{\circ}$ are shown in the left panel. The right panel of Fig. 12 shows the retrieval errors for different SAAs and a fixed SZA of $30^{\circ}$. As can be clearly seen, the retrieval error increases with increasing SZA for $\mathrm{SZA}<70^{\circ}$ and then starts to decrease for $\mathrm{SZA}>80^{\circ}$. For a SZA of $85^{\circ}$ the retrieval errors of similar magnitude as for $50^{\circ}$ are observed. The maximum retrieval error of about $7.5 \%$ at $10 \mathrm{~km}$ altitude occurs for SZAs between $70^{\circ}$ and $80^{\circ}$. Between $30^{\circ}$ and $70^{\circ} \mathrm{SZA}$ the retrieval error changes by about $5 \%$ at $10 \mathrm{~km}$ altitude. The influence of the SAA on the ozone vertical profiles retrieved when neglecting tropospheric clouds is smaller than for the SZA and the maximum 
effect is observed at about $25 \mathrm{~km}$ altitude. For larger SAAs, the errors in the retrieved ozone profiles are smaller.

Similar to the discussion in the previous sections, the observed dependencies can be explained considering the approximate retrieval error as given by Eq. (15). The left panel of Fig. 13 shows the approximate retrieval error as a function of the SZA at different tangent heights. We clearly observe, that the retrieval error is always negative and shows a maximum (in absolute values) between $70^{\circ}$ and $80^{\circ} \mathrm{SZA}$ decreasing for lower and higher Sun which is in line with the results presented in Fig. 12a. A further analysis can be done considering the dependence of the Chappuis triplets on the SZA for a cloudy and for a cloud-free atmosphere as well as of the cloud-free integrated weighting function as shown in the right panel of Fig. 13. As clearly seen, both the Chappuis triplet for a cloudy and for a cloud-free atmosphere decrease with increasing SZA. The Chappuis triplet for a cloudy atmosphere is always larger than that for a cloud-free atmosphere resulting in an underestimation of the ozone concentrations retrieved neglecting the tropospheric clouds (the retrieval error is negative because of the negative integrated weighting function). As follows from the results presented among others by Liou (1973) and Kokhanovsky (2001) for the reflection function of clouds in the visible spectral range, the reflected solar radiation in a cloudy atmosphere decreases with increasing SZA. This explains the observed dependencies for the Chappuis triplet taking into account that, according to our findings in Appendix A, for the typical atmospheric/observation conditions the Chappuis triplet has a similar behaviour as the reflected solar radiation.

In addition, we investigated the ozone profile retrieval errors occurring when neglecting tropospheric clouds for the viewing geometries typical for the Scanning Imaging Absorption Spectrometer for Atmospheric CHartographY (SCIAMACHY) and the Optical Spectrograph and InfraRed Imager System (OSIRIS) instruments. A detailed description of the instruments was presented by Bovensmann et al. (1999) and Llewellyn et al. (2004), respectively. Both Envisat carrying the SCIAMACHY instrument and Odin with the OSIRIS instrument on board are in sun-synchronous polar orbits. SCIAMACHY/Envisat observes scattered, reflected and transmitted solar radiation in nadir, limb-scatter, and solar/lunar occultation modes whereas OSIRIS/Odin performs only limb-scatter observations. The comparison is performed for the viewing conditions of seven SCIAMACHY limb observations (orbit 27746 on 21 June 2007) and for nine combinations of the SZA and SAA which roughly cover the full range of the angles typical for the OSIRIS observations. It is also worth noting that the viewing geometry of the OMPS (Ozone Mapping and Profiler Suite) instrument which will fly on the next generation of US operational polar-orbiting satellites, the National Polar-orbiting Operational Environmental Satellite System (NPOESS), is very similar to that of SCIAMACHY limb-scatter observations.
The relative retrieval errors for the SCIAMACHY viewing geometry are shown in the left panel of Fig. 14. In agreement with the results shown in Fig. 12, the largest retrieval errors occur at SZAs close to $70^{\circ}$. For the considered Envisat orbit, the worst viewing conditions in terms of the sensitivity of the ozone vertical profile retrievals to tropospheric clouds are at $\mathrm{SZA}=68^{\circ}$ and $\mathrm{SAA}=156^{\circ}$ corresponding to observations at southern mid-latitudes and the second worst conditions at $\mathrm{SZA}=63^{\circ}$ and $\mathrm{SAA}=26^{\circ}$ correspond to observations at high northern latitudes. The smallest retrieval errors are observed for $\mathrm{SZA}=25^{\circ}$ and $\mathrm{SAA}=90^{\circ}$ corresponding to measurements in the tropical region.

The relative retrieval errors for the OSIRIS viewing geometry are shown in the right panel of Fig. 14. As expected from Fig. 12, the largest retrieval errors occur for a SZA of $70^{\circ}$ getting smaller for the lower and higher Sun. The dependence on the SAA is weaker as compared to the SZA and is only significant for $\mathrm{SZA}=85^{\circ}$.

\subsection{Most frequent clouds}

In this section, we investigate the relative retrieval errors occurring for the most frequent clouds observed in the Earth's atmosphere. The comparisons are performed for three typical viewing geometries of the SCIAMACHY instrument corresponding to a high, moderate, and low sensitivity of the ozone profile retrievals to the tropospheric clouds (see Sect. 8.5). According to the results published by Rozanov and Kokhanovsky (2006), tropospheric clouds typically extend from 0.5 to $7.5 \mathrm{~km}$ with most frequent values of the geometrical thickness of about $3 \mathrm{~km}$. As demonstrated in previous sections, the ozone profile retrievals exhibit similar sensitivity to low and middle clouds. Therefore, in this study a cloud extending from 4 to $7 \mathrm{~km}$ altitude is considered to be representative for the most frequent clouds in the Earth's atmosphere. Based on the results published by Trishchenko (2001) and Kokhanovsky (2006), respectively, values of $\tau=10$ and $r_{e}=8 \mu \mathrm{m}$ are considered to be representative for the most frequent clouds. As before, the calculations are performed for a surface albedo of 0.3.

The ozone vertical profile retrieval errors for the most frequent clouds are shown in Fig. 15 for three typical SCIAMACHY limb observations having low, moderate, and high sensitivity to tropospheric clouds. During the northern hemispheric summer, these viewing conditions occur in the tropical region $\left(\mathrm{SZA}=25^{\circ}\right.$ and $\left.\mathrm{SAA}=90^{\circ}\right)$, at northern high latitudes $\left(\mathrm{SZA}=85^{\circ}\right.$ and $\mathrm{SAA}=22^{\circ}$ ), and at southern midlatitudes $\left(\mathrm{SZA}=68^{\circ}\right.$ and $\left.\mathrm{SAA}=156^{\circ}\right)$. The obtained results are summarized in Table 3.

\section{Conclusions}

The combined Chappuis and Hartley band retrieval allows to infer ozone profiles in the altitude range from the lower 

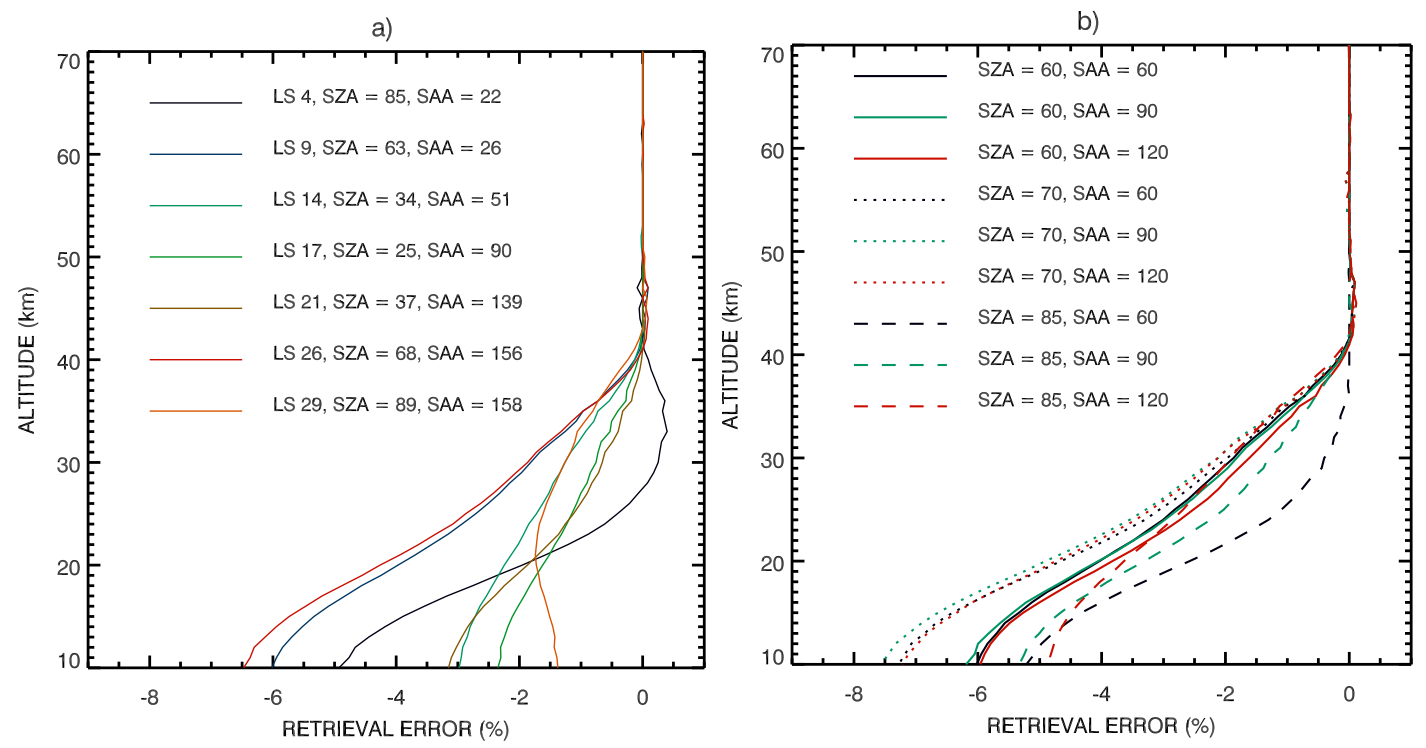

Fig. 14. Relative errors in the retrieved ozone profiles due to neglect of clouds in the retrieval process for viewing geometries typical for SCIAMACHY (left panel) and OSIRIS (right panel) measurements. The calculations were performed for a middle cloud (the same scenario as in Fig. 12).

Table 3. Overview of the sensitivity of ozone vertical profile retrievals to tropospheric clouds (relative retrieval error in $\%$ is shown) for the most frequent clouds ${ }^{\mathrm{a}}$ for typical viewing geometries of the SCIAMACHY instrument.

\begin{tabular}{cccccccc}
\hline Viewing geometries & $15 \mathrm{~km}$ & $20 \mathrm{~km}$ & $30 \mathrm{~km}$ & $40 \mathrm{~km}$ & $50 \mathrm{~km}$ & $60 \mathrm{~km}$ \\
\hline${ }^{\mathrm{b}} \mathrm{SZA}=25^{\circ}, \mathrm{SAA}=90^{\circ}$ & $<2.5$ & $<2$ & $<1$ & $<0.5$ & $<0.1$ & $<0.1$ \\
${ }^{\mathrm{c}} \mathrm{SZA}=85^{\circ}, \mathrm{SAA}=22^{\circ}$ & $<4$ & $<2$ & $<1$ & $<0.5$ & $<0.1$ & $<0.1$ \\
${ }^{\mathrm{d}} \mathrm{SZA}=68^{\circ}, \mathrm{SAA}=156^{\circ}$ & $<6$ & $<5$ & $<2$ & $<0.5$ & $<0.1$ & $<0.1$ \\
\hline
\end{tabular}

stratosphere to the middle mesosphere (15-65 km altitude) using measurements of scattered solar light in limb viewing geometry. The outgoing radiance observed by the instrument is much more sensitive to tropospheric clouds in the visible spectral range than in the UV. Thus, the retrievals are mostly affected by the changes of the Chappuis triplet in a cloudy atmosphere. The maximum retrieval errors are observed in the lower stratosphere. The retrieval errors decrease with increasing altitude and become negligible at about $40 \mathrm{~km}$ for all considered scenarios.

The surface albedo, $\tau$, and SZA are found to have the strongest effect on the retrieved ozone profiles whereas the impact of the $r_{e}$, SAA, cloud geometrical thickness, and cloud top height is rather small. The latter, however, is the only case if the clouds are outside the field of view of the instrument and the cloud optical thickness is not altered when changing the geometrical thickness of the cloud or the effective radius of water droplets. For the most frequent clouds, the ozone vertical profile retrieval error is below $6 \%$ at $15-$ $20 \mathrm{~km}$ altitudes and less than $5 \%$ above $20 \mathrm{~km}$ for typical viewing geometries of the SCIAMACHY instrument.
Beside the investigation of the ozone retrieval errors, we have introduced an approximate method, see Eq. (15), which can be used to estimate the ozone retrieval errors due to neglecting clouds in the retrieval process without solving the full inverse problem.

Future versions of the SCIAMACHY ozone profile retrieval processor operated at the University of Bremen will limit the tangent height range employed in the retrieval to tangent heights above cloud top height. As discussed in Sect. 8.1, this leads to a significant reduction of the effect of clouds on the ozone retrievals in the lower stratosphere.

\section{Appendix A}

In this Appendix, we demonstrate that, for the typical atmospheric/observation conditions, the Chappuis triplet, as a function of any cloud parameter, has a similar behaviour as the reflected nadir solar radiation. This means that, for example, an increase in the reflected radiance, due to a variation of any cloud parameter, leads to an increase in the Chappuis 


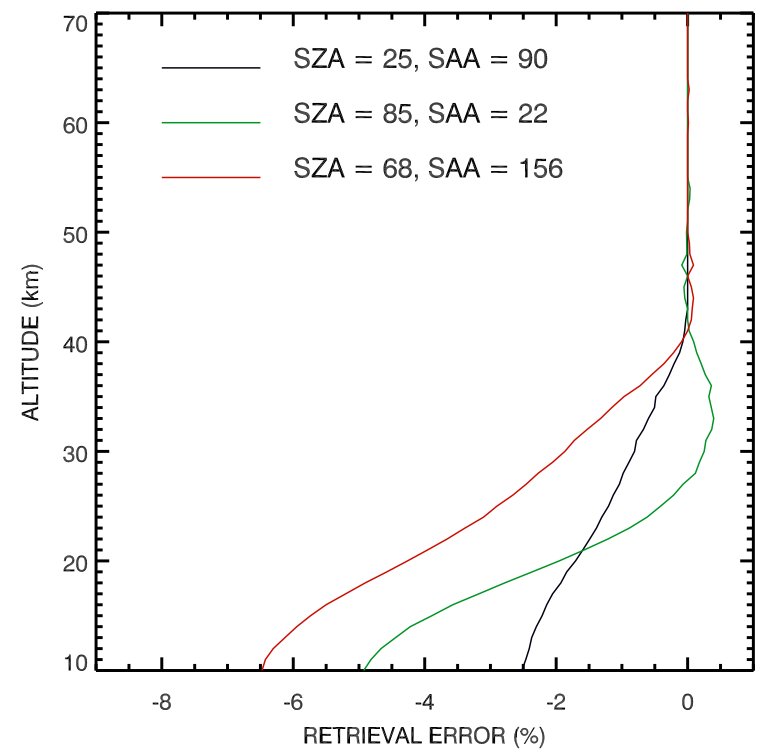

Fig. 15. Relative errors in the retrieved ozone profiles due to neglect of clouds in the retrieval process for most frequent clouds for typical viewing geometries of the SCIAMACHY instrument. The calculations were performed with the scenario as given in Table 2.

triplet value as well. To demonstrate this, let us represent the limb radiance at the wavelength $\lambda_{k}$ and tangent height $h_{i}$ as a sum of the single scattered and the diffuse radiance:

$I\left(\lambda_{k}, h_{i}\right)=I_{s}\left(\lambda_{k}, h_{i}\right)+I_{d}\left(\lambda_{k}, h_{i}\right)$.

Using this representation, Eq. (1) for the normalized limb radiance is rewritten as

$I_{N}\left(\lambda_{k}, h_{i}\right)=\frac{I_{s}\left(\lambda_{k}, h_{i}\right)+I_{d}\left(\lambda_{k}, h_{i}\right)}{I_{S}\left(\lambda_{k}, h_{r}\right)+I_{d}\left(\lambda_{k}, h_{r}\right)}$,

where $h_{r}$ is the reference tangent height, and the Chappuis triplet defined by Eq. (2) is obtained as

$y\left(h_{i}\right)=\frac{I_{N}\left(\lambda_{2}, h_{i}\right)}{\sqrt{I_{N}\left(\lambda_{1}, h_{i}\right) I_{N}\left(\lambda_{3}, h_{i}\right)}}$.

Here, the wavelengths $\lambda_{1}, \lambda_{2}$, and $\lambda_{3}$ are defined as discussed in Sect. 3. Since our consideration is only qualitative, we assume for a further discussion that the normalized radiances at wavelengths $\lambda_{1}$ and $\lambda_{3}$ are equal, i.e., $I_{N}\left(\lambda_{1}, h_{i}\right)=I_{N}\left(\lambda_{3}, h_{i}\right)$. This allows the mathematical formulas presented below to be substantially shortened. Under this assumption, Eq. (A3) results in

$$
\begin{aligned}
y\left(h_{i}\right) & =\frac{I_{s}\left(\lambda_{1}, h_{r}\right)+I_{d}\left(\lambda_{1}, h_{r}\right)}{I_{s}\left(\lambda_{2}, h_{r}\right)+I_{d}\left(\lambda_{2}, h_{r}\right)} \\
& \times \frac{I_{s}\left(\lambda_{2}, h_{i}\right)+I_{d}\left(\lambda_{2}, h_{i}\right)}{I_{s}\left(\lambda_{1}, h_{i}\right)+I_{d}\left(\lambda_{1}, h_{i}\right)},
\end{aligned}
$$

For the discussion below, we restrict our considerations to clouds with top heights below the tangent height $h_{i}$. In this case, the single scattered limb radiation is independent of cloud parameters and the dependence of the normalized limb radiance and of the Chappuis triplet on cloudiness is only due to the diffuse radiation. Let us now simplify Eqs. (A2) and (A4), expanding these into Taylor series with respect to the diffuse radiation and restricting the consideration to the linear terms. In particular, the normalized limb radiance given by Eq. (A2) is written as follows:

$$
\begin{aligned}
I_{N}\left[I\left(\lambda_{k}, h_{i}\right), I\left(\lambda_{k}, h_{r}\right)\right] & =I_{N}\left[I_{s}\left(\lambda_{k}, h_{i}\right), I_{s}\left(\lambda_{k}, h_{r}\right)\right] \\
& +\left.\frac{\partial I_{N}}{\partial I_{d}\left(h_{i}\right)}\right|_{I_{d}=0} I_{d}\left(\lambda_{k}, h_{i}\right) \\
& +\left.\frac{\partial I_{N}}{\partial I_{d}\left(h_{r}\right)}\right|_{I_{d}=0} I_{d}\left(\lambda_{k}, h_{r}\right),
\end{aligned}
$$

where $\partial I_{N} / \partial I_{d}\left(h_{i}\right)$ and $\partial I_{N} / \partial I_{d}\left(h_{r}\right)$ are partial derivatives of the normalized limb radiance with respect to the diffuse radiance at the tangent height $h_{i}$ and $h_{r}$, respectively.

After some algebra, Eq. (A2) can then be rewritten in the following form:

$I_{N}\left(\lambda_{k}, h_{i}\right)=r_{s}^{n}\left\{1+\left[\frac{I_{d}\left(\lambda_{k}, h_{i}\right)}{I_{s}\left(\lambda_{k}, h_{i}\right)}-\frac{I_{d}\left(\lambda_{k}, h_{r}\right)}{I_{S}\left(\lambda_{k}, h_{r}\right)}\right]\right\}$,

where $r_{s}^{n}=I_{s}\left(\lambda_{k}, h_{i}\right) / I_{s}\left(\lambda_{k}, h_{r}\right)$ is the normalized single scattered limb radiance, and Eq. (A4) results in

$$
\begin{aligned}
y\left(h_{i}\right)=r_{s}^{t} & \left\{1+\left[\frac{I_{d}\left(\lambda_{2}, h_{i}\right)}{I_{s}\left(\lambda_{2}, h_{i}\right)}-\frac{I_{d}\left(\lambda_{2}, h_{r}\right)}{I_{s}\left(\lambda_{2}, h_{r}\right)}\right]\right. \\
& \left.-\left[\frac{I_{d}\left(\lambda_{1}, h_{i}\right)}{I_{s}\left(\lambda_{1}, h_{i}\right)}-\frac{I_{d}\left(\lambda_{1}, h_{r}\right)}{I_{s}\left(\lambda_{1}, h_{r}\right)}\right]\right\},
\end{aligned}
$$

where $r_{s}^{t}=I_{s}\left(\lambda_{2}, h_{i}\right) I_{s}\left(\lambda_{1}, h_{r}\right) / I_{s}\left(\lambda_{1}, h_{i}\right) / I_{s}\left(\lambda_{2}, h_{r}\right)$ is the Chappuis triplet value corresponding to the single scattered limb radiation. Both the single scattered and the diffuse limb radiation at the tangent height $h_{i}$ can be represented as follows:

$I_{s, d}\left(\lambda_{k}, h_{i}\right)=\int_{l_{1}}^{l_{2}} \sigma_{k}(l) J_{s, d}\left(\lambda_{k}, l\right) T_{k}(l) d l$,

where the integration is carried out along the instrument lineof-sight, $\sigma_{k}(l)$ is the extinction coefficient at the wavelength $\lambda_{k}, T_{k}(l)=e^{-\tau_{k}\left(l_{1}, l\right)}$ is the transmission function along the line-of-sight between the points having coordinates of $l_{1}$ and $l$, where $l_{1}$ corresponds to the instrument location, $\tau_{k}\left(l_{1}, l\right)$ is the corresponding optical depth, and $J_{s, d}\left(\lambda_{k}, l\right)$ is the source function of the single scattered or the diffuse radiation given by

$$
J_{s, d}\left(\lambda_{k}, l\right)=\frac{\omega_{k}(l)}{4 \pi} \int_{4 \pi} p_{k}(\Omega(l), \Omega) I_{s, d}\left(\lambda_{k}, l, \Omega\right) d \Omega .
$$

Here, $\omega_{k}(l)$ is the single scattering albedo at wavelength $\lambda_{k}$ at the line-of-sight point with coordinate $l, p_{k}(\Omega(l), \Omega)$ is the phase function describing the scattering probability from all directions to the line-of-sight direction, $\Omega:=\{\mu, \phi\}$ describes 
the set of variables $\mu \in[-1,1]$ and $\phi \in[0,2 \pi]$ where $\mu$ is the cosine of the polar angle $\theta$ measured from the positive $\tau$-axis and $\phi$ is the SAA, and $I_{s, d}\left(\lambda_{k}, l, \Omega\right)$ is the single scattered or diffuse radiation field at the line-of-sight point $l$. Assuming that only the tangent point region contributes to the integral along the line-of-sight, Eq. (A8) can be simplified as follows:

$$
I_{s, d}\left(\lambda_{k}, h_{i}\right) \approx \sigma_{k}\left(h_{i}\right) J_{s, d}\left(\lambda_{k}, h_{i}\right) T_{k}\left(h_{i}\right),
$$

where $T_{k}\left(h_{i}\right)$ is the transmission function along the line-ofsight from the the tangent height $h_{i}$ to top of atmosphere. Using Eq. (A10) the ratio of the diffuse to the single scattered radiation can be written as follows:

$\frac{I_{d}\left(\lambda_{k}, h_{i}\right)}{I_{S}\left(\lambda_{k}, h_{i}\right)} \approx \frac{J_{d}\left(\lambda_{k}, h_{i}\right)}{J_{S}\left(\lambda_{k}, h_{i}\right)}$.

Substituting the ratio $I_{d}\left(\lambda_{k}, h_{i}\right) / I_{s}\left(\lambda_{k}, h_{i}\right)$ as given by Eq. (A11) into Eqs. (A6) and (A7), we obtain

$I_{N}\left(\lambda_{k}, h_{i}\right)=r_{s}^{n}\left\{1+\left[\frac{J_{d}\left(\lambda_{k}, h_{i}\right)}{J_{s}\left(\lambda_{k}, h_{i}\right)}-\frac{J_{d}\left(\lambda_{k}, h_{r}\right)}{J_{s}\left(\lambda_{k}, h_{r}\right)}\right]\right\}$

and

$$
\begin{aligned}
y\left(h_{i}\right)=r_{s}^{t} & \left\{1+\left[\frac{J_{d}\left(\lambda_{2}, h_{i}\right)}{J_{s}\left(\lambda_{2}, h_{i}\right)}-\frac{J_{d}\left(\lambda_{2}, h_{r}\right)}{J_{s}\left(\lambda_{2}, h_{r}\right)}\right]\right. \\
& \left.-\left[\frac{J_{d}\left(\lambda_{1}, h_{i}\right)}{J_{s}\left(\lambda_{1}, h_{i}\right)}-\frac{J_{d}\left(\lambda_{1}, h_{r}\right)}{J_{s}\left(\lambda_{1}, h_{r}\right)}\right]\right\} .
\end{aligned}
$$

In the next step, let us formulate an approximate relationship between the diffuse source function, $J_{d}\left(\lambda_{k}, h_{i}\right)$, and the intensity of radiation reflected by a cloud. This is done using the approximate expression for the intensity of diffuse radiation suggested by Kokhanovsky and Rozanov (2004) which we write here in the following form:

$$
R(\Omega)=R_{s}(\Omega)+T\left(\mu_{0} ; H, h_{c}\right) R_{c}(\Omega) T\left(\mu ; h_{i}, h_{c}\right),
$$

where $R_{S}(\Omega)$ is the intensity of radiation scattered in the atmosphere above the cloud calculated in the single scattering approximation, $R_{c}(\Omega)$ is the intensity of radiation scattered within the cloud and in the underlying atmosphere including the surface reflection (we neglect the dependence of $R_{c}(\Omega)$ on the wavelength within the Chappuis ozone absorption band), $\mu_{0}$ is a cosine of the SZA, $T\left(\mu_{0} ; H, h_{c}\right)=e^{-\tau\left(H, h_{c}\right) / \mu_{0}}$ is the transmission between the top of the atmosphere $(H)$ and the cloud top height $\left(h_{c}\right)$, and $T\left(\mu ; h_{i}, h_{c}\right)=e^{-\tau\left(h_{i}, h_{c}\right) / \mu}$ is the transmission between the cloud top height $\left(h_{c}\right)$ and the tangent point $\left(h_{i}\right)$. In the case of a weak gaseous absorption, the first term on the right-hand side of Eq. (A14) is much smaller than the second term and, thus, it can be neglected. Substituting then Eq. (A14) into Eq. (A9), the following approximate expression for the diffuse source function can be obtained:

$$
\begin{aligned}
J_{d}\left(\lambda_{k}, h_{i}\right) & \approx \frac{\omega_{k}\left(h_{i}\right)}{4 \pi} \int_{4 \pi} p_{k}\left(\Omega_{i}, \Omega\right) R_{c}(\Omega) T_{k}\left(\mu ; h_{i}, h_{c}\right) d \Omega \\
& \times T_{k}\left(\mu_{0} ; H, h_{c}\right) .
\end{aligned}
$$

Taking into account that

$I_{s}\left(\lambda_{k}, l, \Omega\right)=\pi \delta\left(\Omega-\Omega_{0}\right) T_{k}\left(\mu_{0} ; H, h_{i}\right)$,

where $\delta\left(\Omega-\Omega_{0}\right)$ is the Dirac delta function and the extraterrestrial solar flux is set to $\pi$, Eq. (A9) for the single scattering source function becomes

$J_{s}\left(\lambda_{k}, h_{i}\right)=\frac{\omega_{k}\left(h_{i}\right)}{4} p_{k}\left(\Omega_{i}, \Omega_{0}\right) T_{k}\left(\mu_{0} ; H, h_{i}\right)$

and the ratio of the diffuse to the single scattering source function at the tangent height $h_{i}$ can be written as follows:

$$
\begin{aligned}
\frac{J_{d}\left(\lambda_{k}, h_{i}\right)}{J_{s}\left(\lambda_{k}, h_{i}\right)} & =\frac{1}{\pi} \int_{4 \pi} \tilde{p}_{k}\left(\Omega_{i}, \Omega\right) R_{c}(\Omega) T_{k}\left(\mu ; h_{i}, h_{c}\right) d \Omega \\
& \times T_{k}\left(\mu_{0} ; h_{i}, h_{c}\right),
\end{aligned}
$$

where $\quad \tilde{p}_{k}\left(\Omega_{i}, \Omega\right)=p_{k}\left(\Omega_{i}, \Omega\right) / p_{k}\left(\Omega_{i}, \Omega_{0}\right), \quad$ and $T_{k}\left(\mu_{0} ; h_{i}, h_{c}\right)=T_{k}\left(\mu_{0} ; H, h_{c}\right) / T_{k}\left(\mu_{0} ; H, h_{i}\right)$ is the transmission between the tangent height $h_{i}$ and the cloud top height altitude $h_{c}$. The ratio of the diffuse to the single scattering source function at the reference tangent height can be obtained setting in Eq. (A18) $h_{i}=h_{r}$. To simplify Eq. (A18) let us introduce the following abbreviation for the product of two transmission functions:

$T_{k}\left(h_{i}, h_{c}\right)=T_{k}\left(\mu ; h_{i}, h_{c}\right) T_{k}\left(\mu_{0} ; h_{i}, h_{c}\right)$.

Now, Eq. (A18) can be rewritten as follows:

$\frac{J_{d}\left(\lambda_{k}, h_{i}\right)}{J_{s}\left(\lambda_{k}, h_{i}\right)}=\frac{1}{\pi} \int_{4 \pi} \tilde{p}_{k}\left(\Omega_{i}, \Omega\right) R_{c}(\Omega) T_{k}\left(h_{i}, h_{c}\right) d \Omega$.

Introducing an auxiliary function $\mathcal{T}\left(\lambda_{k}\right)$ as

$\mathcal{T}\left(\lambda_{k}\right)=\frac{J_{d}\left(\lambda_{k}, h_{i}\right)}{J_{s}\left(\lambda_{k}, h_{i}\right)}-\frac{J_{d}\left(\lambda_{k}, h_{r}\right)}{J_{s}\left(\lambda_{k}, h_{r}\right)}$,

Eqs. (A12) and (A13) can be rewritten as follows:

$$
\begin{aligned}
& I_{N}\left(\lambda_{k}, h_{i}\right)=r_{s}^{n}\left[1+\mathcal{T}\left(\lambda_{k}\right)\right], \\
& y\left(h_{i}\right)=r_{s}^{t}\left[1+\mathcal{T}\left(\lambda_{2}\right)-\mathcal{T}\left(\lambda_{1}\right)\right] .
\end{aligned}
$$

These equations alone with Eqs. (A20) and (A21) provide a simple linear relationship between the normalized limb radiance $I_{N}\left(\lambda_{k}, h_{i}\right)$ or the Chappuis triplet value $y\left(h_{i}\right)$ on the one hand and the intensity of radiation reflected by a cloud $R_{c}(\Omega)$ on the other.

The goal of our study is to prove that if the intensity of reflected radiation increases due to an increase in a certain cloud parameter, for example $\tau$, i.e.,

$\frac{\partial R_{c}(\Omega)}{\partial \tau}=R_{c}^{\prime}(\Omega)>0$,

then $\partial I_{N}\left(\lambda_{k}, h_{i}\right) / \partial \tau>0$ and $\partial y\left(h_{i}\right) / \partial \tau>0$ as well, i.e., both the normalized limb radiance and the Chappuis triplet increase when the intensity of reflected radiation increases. The discussion below is applicable to nearly all cloud parameters except for the cloud top height. This is because, 
unlike other cloud parameters, the variation in the cloud top height affects not only the solar radiation reflected by cloud in Eq. (A14) but also the transmissions $T\left(\mu_{0} ; H, h_{c}\right)$ and $T\left(\mu ; h_{i}, h_{c}\right)$ which must be differentiated as well when calculating the derivative of $R(\Omega)$. Since, as shown in Sect. 8.3, the dependence of the ozone vertical profile retrievals on cloud top height is rather small, we exclude this parameter from the consideration below for a sake of simplicity.

Differentiating Eqs. (A22) and (A23) with respect to the cloud parameter of interest, we obtain

$$
\begin{aligned}
& I_{N}^{\prime}\left(\lambda_{k}, h_{i}\right)=r_{s}^{n}\left[1+\mathcal{T}^{\prime}\left(\lambda_{k}\right)\right], \\
& y^{\prime}\left(h_{i}\right)=r_{s}^{t}\left[1+\mathcal{T}^{\prime}\left(\lambda_{2}\right)-\mathcal{T}^{\prime}\left(\lambda_{1}\right)\right] .
\end{aligned}
$$

Here, taking into account Eqs. (A20) and (A21), the derivative $\mathcal{T}^{\prime}\left(\lambda_{k}\right)$ is obtained as

$$
\begin{aligned}
\mathcal{T}^{\prime}\left(\lambda_{k}\right) & =\frac{1}{\pi} \int_{4 \pi} \tilde{p}_{k}\left(\Omega_{i}, \Omega_{0}\right) R_{c}^{\prime}(\Omega) \\
& \times\left[T_{k}\left(h_{i}, h_{c}\right)-T_{k}\left(h_{r}, h_{c}\right)\right] d \Omega .
\end{aligned}
$$

or

$$
\begin{aligned}
\mathcal{T}^{\prime}\left(\lambda_{k}\right) & =\frac{1}{\pi} \int_{4 \pi} \tilde{p}_{k}\left(\Omega_{i}, \Omega_{0}\right) R_{c}^{\prime}(\Omega) T_{k}\left(h_{i}, h_{c}\right) \\
& \times\left[1-T_{k}\left(h_{r}, h_{i}\right)\right] d \Omega,
\end{aligned}
$$

where $T_{k}\left(h_{r}, h_{i}\right)=T_{k}\left(h_{r}, h_{c}\right) / T_{k}\left(h_{i}, h_{c}\right)$ is the transmission between the reference tangent height $h_{r}$ and the tangent height $h_{i}$. Now it is obvious that

$\mathcal{T}^{\prime}\left(\lambda_{k}\right)>0$, if $R_{c}^{\prime}(\Omega)>0$

Thus, we found that the derivative of the normalized limb radiance with respect to a cloud parameter has the same sign as the derivative of the intensity the solar radiation reflected by the cloud.

To complete our discussion, we show that the corresponding derivative of the Chappuis triplet has the same sign as well, i.e., we prove that $\mathcal{T}^{\prime}\left(\lambda_{2}\right)-\mathcal{T}^{\prime}\left(\lambda_{1}\right)>0$. This can be done taking into account that the ozone absorption at wavelength $\lambda_{2}$ is larger than at $\lambda_{1}$. This allows us to rewrite Eq. (A27) for $\lambda_{2}$ in the following form:

$$
\begin{aligned}
\mathcal{T}^{\prime}\left(\lambda_{2}\right) & =\frac{1}{\pi} \int_{4 \pi} \tilde{p}_{2}\left(\Omega_{i}, \Omega_{0}\right) R_{c}^{\prime}(\Omega)\left[T_{1}\left(h_{i}, h_{c}\right) T_{g}\left(h_{i}, h_{c}\right)\right. \\
& \left.-T_{1}\left(h_{r}, h_{c}\right) T_{g}\left(h_{r}, h_{c}\right)\right] d \Omega,
\end{aligned}
$$

where $T_{g}\left(h_{i}, h_{c}\right)$ and $T_{g}\left(h_{r}, h_{c}\right)$ describe additional gaseous absorption at wavelength $\lambda_{2}$ as compared to wavelength $\lambda_{1}$. Now, taking into account that $T_{1}\left(h_{r}, h_{c}\right)=T_{1}\left(h_{r}, h_{i}\right) T_{1}\left(h_{i}, h_{c}\right)$, the difference
$\mathcal{T}^{\prime}\left(\lambda_{2}\right)-\mathcal{T}^{\prime}\left(\lambda_{1}\right)$ can be written as

$$
\begin{aligned}
\mathcal{T}^{\prime}\left(\lambda_{2}\right)-\mathcal{T}^{\prime}\left(\lambda_{1}\right)= & \frac{1}{\pi} \int_{4 \pi} \tilde{p}_{2}\left(\Omega_{i}, \Omega_{0}\right) R_{c}^{\prime}(\Omega) T_{1}\left(h_{i}, h_{c}\right) \\
& \times\left\{\left[T_{g}\left(h_{i}, h_{c}\right)-T_{1}\left(h_{r}, h_{i}\right) T_{g}\left(h_{r}, h_{c}\right)\right]\right. \\
& \left.-\left[1-T_{1}\left(h_{r}, h_{i}\right)\right]\right\} d \Omega .
\end{aligned}
$$

As seen from this equation, in contrast to $\mathcal{T}^{\prime}\left(\lambda_{k}\right)$, the difference $\mathcal{T}^{\prime}\left(\lambda_{2}\right)-\mathcal{T}^{\prime}\left(\lambda_{1}\right)$ can be both negative and positive. Indeed, assuming that the absorption between $h_{i}$ and $h_{c}$ can be neglected, i.e., $T_{g}\left(h_{i}, h_{c}\right)=1$, the expression in brackets results in

$$
\begin{aligned}
\{\} & =T_{1}\left(h_{r}, h_{i}\right)-T_{1}\left(h_{r}, h_{i}\right) T_{g}\left(h_{r}, h_{c}\right) \\
& =T_{1}\left(h_{r}, h_{i}\right)\left[1-T_{g}\left(h_{r}, h_{c}\right)\right],
\end{aligned}
$$

and $\mathcal{T}^{\prime}\left(\lambda_{2}\right)-\mathcal{T}^{\prime}\left(\lambda_{1}\right)>0$. On the other hand, assuming that gaseous absorption is very strong, i.e., $T_{g}\left(h_{i}, h_{c}\right)=T_{g}\left(h_{r}, h_{c}\right)=0$, we have

\{\}$=-\left[1-T_{1}\left(h_{r}, h_{i}\right)\right]$,

i.e., $\mathcal{T}^{\prime}\left(\lambda_{2}\right)-\mathcal{T}^{\prime}\left(\lambda_{1}\right)<0$. Thus, generally, the sign of the difference $\mathcal{T}^{\prime}\left(\lambda_{2}\right)-\mathcal{T}^{\prime}\left(\lambda_{1}\right)$ depends on the gaseous absorption in the atmosphere. In the considered case of measurements of scattered solar light in the Chappuis absorption band of ozone, it is reasonable to assume that the gaseous absorption and atmospheric extinction between the tangent heights $h_{r}$ and $h_{i}$ is weak. Under this assumption, we have

$$
\begin{aligned}
& T_{1}\left(h_{r}, h_{i}\right) \approx 1-\tau_{1}\left(h_{r}, h_{i}\right), \\
& T_{g}\left(h_{r}, h_{c}\right) \approx 1-\tau_{g}\left(h_{r}, h_{c}\right),
\end{aligned}
$$

where $\tau_{1}\left(h_{r}, h_{i}\right)$ and $\tau_{g}\left(h_{r}, h_{c}\right)$ are the optical thicknesses of the extinction (Rayleigh scattering and ozone absorption at $\lambda_{1}$ ) and of the gaseous absorption, respectively (we remind that we neglect the aerosol extinction and the gaseous absorption should be understood as additional absorption at wavelength $\lambda_{2}$ as compared to wavelength $\lambda_{1}$ ). Substituting now these approximations into Eq. (A31) and neglecting the quadratic terms, i.e., $\tau_{1}\left(h_{r}, h_{i}\right) \tau_{g}\left(h_{r}, h_{c}\right)$, after simple algebra we obtain

$$
\begin{aligned}
\mathcal{T}^{\prime}\left(\lambda_{2}\right)-\mathcal{T}^{\prime}\left(\lambda_{1}\right) & =\frac{1}{\pi} \int_{4 \pi} \tilde{p}_{2}\left(\Omega_{i}, \Omega_{0}\right) R_{c}^{\prime}(\Omega) T_{1}\left(h_{i}, h_{c}\right) \\
& \times \tau_{g}\left(h_{r}, h_{i}\right) d \Omega .
\end{aligned}
$$

Thus, we can state that the derivative of the triplet, with respect to the cloud parameters, has the same sign as the derivative of the intensity of solar radiation reflected by clouds if the difference in gaseous absorption between the wavelengths forming the triplet is small and the extinction of the radiation between tangent heights $h_{r}$ and $h_{i}$ due to the scattering processes is small as well. Although these assumptions commonly hold, in the case of very large ozone concentrations Eq. (A35) is not valid anymore and the signs of 
the derivatives can be different. Thus, the sensitivity of the triplet to clouds can not be explained considering the intensity of the reflected solar radiation in this case.

Acknowledgements. This work was supported by the European Space Agency (ESA), the German aerospace center (DLR) and the University of Bremen, Germany. SCIAMACHY is jointly funded by Germany, the Netherlands and Belgium. T. S. would like to thank Lampang Rajabhat University, Thailand for the scholarship support.

Edited by: J. Joiner

\section{References}

Bovensmann, H., Burrows, J. P., Buchwitz, M., Frerick, J., Noël, S., Rozanov, V. V., Chance, K. V., and Goede, A. P. H.: SCIAMACHY: Mission Objectives and Measurement Modes, J. Atmos. Sci., 56, 127-150, 1999.

Bracher, A., Bovensmann, H., Bramstedt, K., Burrows, J. P., von Clarmann, T., Eichmann, K.-U., Fischer, H., Funke, B., GilLopez, S., Glatthor, N., Grabowski, U., Höpfner, M., Kaufmann, M., Kellmann, S., Kiefer, M., Koukouli, M. E., Linden, A., Lopez-Puertas, M., Mengistu Tsidu, G., Milz, M., Noël, S., Rohen, G., Rozanov, A., Rozanov, V. V., von Savigny, C., Sinnhuber, M., Skupin, J., Steck, T., Stiller, G. P., Wang, D.-Y., Weber, M., and Wuttke, M. W.: Cross comparisons of $\mathrm{O}_{3}$ and $\mathrm{NO}_{2}$ measured by the atmospheric ENVISAT instruments GOMOS, MIPAS, and SCIAMACHY, Adv. Space Res., 36, 855867, doi:10.1016/j.asr.2005.04.005, 2005.

Butz, A., Bösch, H., Camy-Peyret, C., Chipperfield, M., Dorf, M., Dufour, G., Grunow, K., Jeseck, P., Kühl, S., Payan, S., Pepin, I., Pukite, J., Rozanov, A., von Savigny, C., Sioris, C., Wagner, T., Weidner, F., and Pfeilsticker, K.: Inter-comparison of stratospheric $\mathrm{O}_{3}$ and $\mathrm{NO}_{2}$ abundances retrieved from balloon borne direct sun observations and Envisat/SCIAMACHY limb measurements, Atmos. Chem. Phys., 6, 1293-1314, 2006, http://www.atmos-chem-phys.net/6/1293/2006/.

Degenstein, D. A., Bourassa, A. E., Roth, C. Z., and Llewellyn, E. J.: Limb-scatter ozone retrieval from 10 to $60 \mathrm{~km}$ using a multiplicative algebraic reconstruction technique, Atmos. Chem. Phys., 9, 6521-6529, 2009,

http://www.atmos-chem-phys.net/9/6521/2009/.

Dupuy, E., Walker, K. A., Kar, J., Boone, C. D., McElroy, C. T., Bernath, P. F., Drummond, J. R., Skelton, R., McLeod, S. D., Hughes, R. C., Nowlan, C. R., Dufour, D. G., Zou, J., Nichitiu, F., Strong, K., Baron, P., Bevilacqua, R. M., Blumenstock, T., Bodeker, G. E., Borsdorff, T., Bourassa, A. E., Bovensmann, H., Boyd, I. S., Bracher, A., Brogniez, C., Burrows, J. P., Catoire, V., Ceccherini, S., Chabrillat, S., Christensen, T., Coffey, M. T., Cortesi, U., Davies, J., De Clercq, C., Degenstein, D. A., De Mazière, M., Demoulin, P., Dodion, J., Firanski, B., Fischer, H., Forbes, G., Froidevaux, L., Fussen, D., Gerard, P., Godin-Beekmann, S., Goutail, F., Granville, J., Griffith, D., Haley, C. S., Hannigan, J. W., Höpfner, M., Jin, J. J., Jones, A., Jones, N. B., Jucks, K., Kagawa, A., Kasai, Y., Kerzenmacher, T. E., Kleinböhl, A., Klekociuk, A. R., Kramer, I., Küllmann, H., Kuttippurath, J., Kyrölä, E., Lambert, J.-C., Livesey, N. J., Llewellyn, E. J., Lloyd, N. D., Mahieu, E., Manney, G. L., Mar- shall, B. T., McConnell, J. C., McCormick, M. P., McDermid, I. S., McHugh, M., McLinden, C. A., Mellqvist, J., Mizutani, K., Murayama, Y., Murtagh, D. P., Oelhaf, H., Parrish, A., Petelina, S. V., Piccolo, C., Pommereau, J.-P., Randall, C. E., Robert, C., Roth, C., Schneider, M., Senten, C., Steck, T., Strandberg, A., Strawbridge, K. B., Sussmann, R., Swart, D. P. J., Tarasick, D. W., Taylor, J. R., Tétard, C., Thomason, L. W., Thompson, A. M., Tully, M. B., Urban, J., Vanhellemont, F., Vigouroux, C., von Clarmann, T., von der Gathen, P., von Savigny, C., Waters, J. W., Witte, J. C., Wolff, M., and Zawodny, J. M.: Validation of ozone measurements from the Atmospheric Chemistry Experiment (ACE), Atmos. Chem. Phys., 9, 287-343, 2009, http://www.atmos-chem-phys.net/9/287/2009/.

Erle, F., Pfeilsticker, K., and Platt, U.: On the influence of tropospheric clouds on zenith-scattered-light measurements of stratospheric species, Geophys. Res. Lett., 22, 2725-2728, 1995.

Flittner, D. E., Bhartia, P. K., and Herman, B. M.: $\mathrm{O}_{3}$ profiles retrieved from limb-scatter measurements: Theory, Geophys. Res. Lett., 27, 2601-2604, 2000.

Haley, C. S., Brohede, S. M., Sioris, C. E., Griffioen, E., Murtagh, D. P., McDade, I. C., Eriksson, P., Llewellyn, E. J., Bazureau, A., and Goutail, F.: Retrieval of stratospheric $\mathrm{O}_{3}$ and $\mathrm{NO}_{2}$ profiles from Odin Optical Spectrograph and Infrared Imager System (OSIRIS) Limb-Scattered Sunlight Measurements, J. Geophys. Res., 109, D16303, doi:10.1029/2004JD004588, 2004.

Hansen, J. E. and Travis, L. D.: Light scattering in planetary atmospheres, Space Sci. Rev., 16, 527-610, 1974.

Hendrick, F., Van Roozendael, M., Kylling, A., Petritoli, A., Rozanov, A., Sanghavi, S., Schofield, R., von Friedeburg, C., Wagner, T., Wittrock, F., Fonteyn, D., and De Mazière, M.: Intercomparison exercise between different radiative transfer models used for the interpretation of ground-based zenith-sky and multiaxis DOAS observations, Atmos. Chem. Phys., 6, 93-108, 2006, http://www.atmos-chem-phys.net/6/93/2006/.

Kokhanovsky, A. A.: Optics of light scattering media: Problems and Solutions, Springer, Berlin, 2001.

Kokhanovsky, A. A.: Optical properties of terrestrial clouds, EarthSci. Rev., 64, 189-241, 2004.

Kokhanovsky, A. A. and Rozanov, V. V.: The physical parameterization of the top-of-atmosphere reflection function for a cloudy atmosphere-underlying surface system: the oxygen A-band case study, J. Quant. Spectr. Rad. Trans., 85, 35-55, 2004.

Kokhanovsky, A. A.: Cloud Optics, Springer, Berlin, 2006.

Kokhanovsky, A. A., Bovensmann, H., Burrows, J. P., Lotz, W., Rozanov, V., Schreier, M., Vountas, M., and von HoyningenHuene, W.: SACURA: A new Semi-Analytical CloUd Retrieval Algorithm, http://www.iup.uni-bremen.de/ $\sim$ sciaproc/ SACURA/, 2008.

Kurosu, T., Rozanov V. V., and Burrows J. P.: Parameterization schemes for terrestrial water clouds in the radiative transfer model GOMETRAN, J. Geophys., Res., 102, 21809-21823, 1997.

Kylling A., Albold, A., and Seckmeyer, G.: Transmittance of a cloud is wavelength-dependent in the UV-range: Physical interpretation, Geophys. Res. Lett., 24(4), 397-400, 1997.

Lelieveld, J., Crutzen, P. J., and Rodhe, H.: Zonal average cloud characteristics for global atmospheric chemistry modelling, Report CM-76, Department of Meteorology, University of Stockholm, 1989. 
Liou, K. N.: A numerical experiment on Chandrasekhar's DiscreteOrdinate method for radiative transfer: Applications to cloudy and hazy atmospheres, J. Atmos. Sci., 30, 1303-1326, 1973.

Liou, K. N.: On the absorption, reflection and transmission of solar radiation in cloudy atmospheres, J. Atmos. Sci., 33, 798-805, 1976.

Llewellyn, E. J., Lloyd, N. D., Degenstein, D. A., Gattinger, R. L., Petelina, S. V., Bourassa, A. E., Wiensz, J. T., Ivanov, E. V., McDade, I. C., Solheim, B. H., McConnell, J. C., Haley, C. S., von Savigny, C., Sioris, C. E., McLinden, C. A., Griffioen, E., Kaminski, J., Evans, W. F. J., Puckrin, E., Strong, K., Wehrle, V., Hum, R. H., Kendall, D. J. W., Matsushita, J., Murtagh, D. P., Brohede, S., Stegman, J., Witt, G., Barnes, G., Payne, W. F., Piche, L., Smith, K., Warshaw, G., Deslauniers, D.-L., Marchand, P., Richardson, E. H., King, R. A., Wevers, I., McCreath, W., Kyrölä, E., Oikarinen, L., Leppelmeier, G. W., Auvinen, H., Mégie, G., Hauchecorne, A., Lefevre, F., de La Nöe, J., Ricaud, P., Frisk, U., Sjoberg, F., von Scheele, F., and Nordh, L.: The OSIRIS instrument on the Odin satellite, Can. J. Phys., 82, 411422, doi:10.1139/P04-005, 2004.

Loughman, R. P., Griffioen, E., Oikarinen, L., Postylyakov, O. V., Rozanov, A., Flittner, D. E., and Rault, D. F.: Comparison of radiative transfer models for limb-viewing scattered sunlight measurements, J. Geophys. Res., 109, D06303, doi:10.1029/2003JD003854, 2004.

Loughman R. P., Flittner, D. E., Herman, B. M., Bhartia, P. K., Hilsenrath, E., and McPeters, R. D.: Description and sensitivity analysis of a limb-scattering ozone retrieval algorithm, J. Geophys. Res., 110, D19301, doi:10.1029/2004JD005429, 2005.

Mace, G. G., Marchand, R., Zhang, Q., and Stephens, G.: Global hydrometeor occurrence as observed by CloudSat: Initial observations from summer 2006, Geophys. Res. Lett., 34, L09808, doi:10.1029/2006GL029017, 2007.

McPeters, R. D., Janz, S. J., Hilsenrath, E., Brown, T. L., Flittner, D. E., and Heath, D. F.: The retrieval of $\mathrm{O}_{3}$ profiles from limb-scatter measurements: Results from the Shuttle Ozone Limb Sounding Experiment, Geophys. Res. Lett., 27, 25972600, 2000.

Murtagh, D., Frisk, U., Merino, F., Ridal, M., Jonsson, A., Stegman, J., Witt, G., Eriksson, P., Jimenez, C., Mégie, G., de la Nöe, J., Ricaud, P., Baron, P., Pardo, J., Hauchcorne, A., Llewellyn, E. J., Degenstein, D. A., Gattinger, R. L., Lloyd, N. D., Evans, W. F. J., McDade, I. C., Haley, C. S., Sioris, C., von Savigny, C., Solheim, B. H., McConnell, J. C., Strong, K., Richardson, E. H., Leppelmeier, G. W., Kyrölä, E., Auvinen, H., and Oikarinen L.: An overview of the Odin Atmospheric Mission, Can. J. Phys., 80(S1), 309-319, 2002.

Nakajima, T. and King, M. D.: Determination of the optical thickness and effective particle radius of clouds from reflected solar radiation measurements. Part I: Theory, J. Atmos. Res., 48, 1878-1893, 1990.

Oikarinen, L., Sihvola, E., and Kyrölä, E.: Multiple scattering radiance in limb-viewing geometry, J. Geophys. Res., 104, 3126131274, 1999.

Prather, M. J. and Remsberg, E. E. (Eds.): The Atmospheric Effects of Stratospheric Aircraft: Report of the 1992 Models and Measurements Workshop. NASA Reference Publication 1292, Vols. 1-3, National Aeronautics and Space Administration, Washington, D.C., USA, 1993.
Pruppacher, H. R. and Jaenicke, R.: The processing of water vapor and aerosols by atmospheric clouds, a global estimation, Atmos. Res., 38, 283-295, 1995.

Rault, D. F.: Ozone profile retrieval from Stratospheric Aerosol and Gas Experiment (SAGE III) limb-scatter measurements, J. Geophys. Res., 110, D09309, doi:10.1029/2004JD004970, 2005.

Rodgers, C. D.: Retrieval of atmospheric temperature and composition from remote measurements of thermal radiation, Rev. Geophys. Space Phys., 14, 609-624, 1976.

Roebeling, R. A., Berk, A., Feijt, A. J., Frerichs, W., Joliver, D., Macke, A., and Stammes, P.: Sensitivity of cloud property retrievals to differences in radiative transfer simulations, KNMI WR2005-02, 2005.

Rohen, G.: Retrieval of upper stratospheric/lower mesospheric ozone profiles from SCIAMACHY limb-scatter measurements and observations of the ozone depletion during the solar proton event in Oct./Nov. 2003, PhD thesis, University of Bremen, Bremen, Germany, 2006.

Rohen, G., von Savigny, C., Llewellyn, E., Kaiser, J. W., Eichmann, K.-U., Bracher, A., Bovensmann, H., and Burrows, J. P.: First results of ozone profiles between 35 and $65 \mathrm{~km}$ retrieved from SCIAMACHY limb spectra and observations of ozone depletion during the solar proton events in October/November 2003, Adv. Space Res., 37(12), 2263-2268, 2006.

Rossow, W. B. and Schiffer, R. A.: Advances in understanding clouds from ISCCP, B. Am. Meteorol. Soc., 80, 2261-2288, doi:10.1175/1520-0477(1999)080, 1999.

Roth, C. Z., Degenstein, D. A., Bourassa, A. E., and Llewellyn, E. J.: The retrieval of vertical profiles of ozone number density using Chappuis band absorption information and a multiplicative algebraic reconstruction technique, Can. J. Phys., 85, 12251243, 2007.

Rozanov A., Rozanov, V., and Burrows, J. P.: A numerical radiative transfer model for a spherical planetary atmosphere: combined differential-integral approach involving the Picard iterative approximation, J. Quant. Spectr. Rad. Trans., 69(4), 491-512, 2001.

Rozanov A., Bovensmann, H., Bracher, A., Hrechanyy, S., Rozanov, V., Sinnhuber, M., Stroh, F., and Burrows, J. P.: $\mathrm{NO}_{2}$ and $\mathrm{BrO}$ vertical profile retrieval from SCIAMACHY limb measurements: Sensitivity studies, Adv. Space Res., 36(5), 846-854, doi:10.1016/j.asr.2005.03.013, 2005a.

Rozanov, A., Rozanov, V., Buchwitz, M., Kokhanovsky, A., and Burrows, J. P.: SCIATRAN 2.0 - A new radiative transfer model for geophysical applications in the $175-2400 \mathrm{~nm}$ spectral region, Adv. Space Res., 36, 1015-1019, 2005b.

Rozanov, A., Eichmann, K.-U., von Savigny, C., Bovensmann, H., Burrows, J. P., von Bargen, A., Doicu, A., Hilgers, S., GodinBeekmann, S., Leblanc, T., and McDermid, I. S.: Comparison of the inversion algorithms applied to the ozone vertical profile retrieval from SCIAMACHY limb measurements, Atmos. Chem. Phys., 7, 4763-4779, 2007, http://www.atmos-chem-phys.net/7/4763/2007/.

Rozanov, A.: SCIATRAN 2.X: Radiative transfer model and retrieval software package, http://www.iup.physik.uni-bremen.de/ sciatran, 2008.

Rozanov, V. V. and Kokhanovsky, A. A.: Semianalytical cloud retrieval algorithm as applied to the cloud top altitude and the cloud geometrical thickness determination from top-of-atmosphere re- 
flectance measurements in the oxygen A-band, J. Geophys. Res., 109, D05202, doi:10.1029/2003JD004104, 2004.

Rozanov, V. V. and Kokhanovsky, A. A.: Determination of cloud geometrical thickness using backscattered solar light in a gaseous absorption band, IEEE Geosci. Remote Sens. Lett., 3(2), 250253, 2006.

Rozanov, V. V.: Adjoint radiative transfer equation and inverse problems, in: Light Scattering Reviews, edited by: Kokhanovsky, A. A., Springer, Praxis Publishing, Chichester, UK, 339-390, 2006.

Rozanov, V. V. and Kokhanovsky, A. A.: Impact of single- and multi-layered cloudiness on ozone vertical column retrievals using nadir observations of backscattered solar radiation, in: Light Scattering Reviews 3, edited by: Kokhanovsky, A. A., Springer, Praxis Publishing, Chichester, UK, 133-189, 2008.

Rusch, D. W., Mount, G. H., Barth, C. A., Rottmann, G. J., Thomas, R. J., Thomas, G. E., Sanders, R. W., Lawrence, G. M., and Eckman, R. S.: Ozone densities in the lower mesosphere measured by a limb scanning UltraViolet Spectrometer, Geophys. Res. Lett., 10(4), 241-244, 1983.

Siewert, C. E.: A discrete-ordinates solution for radiative-transfer models that include polarization effects, J. Quant. Spectr. Rad. Trans., 64, 227-254, 2000.

Sioris, C. E., Haley, C. S., McLinden, C. A., von Savigny C., McDade, I. C., McConnell, J. C., Evans, W. F. J., Lloyd, N. D., Llewellyn, E. J., Chance, K. V., Kurosu, T. P., Murtagh, D., Frisk, U., Pfeilsticker, K., Bösch, H., Weidner, F., Strong, K., Stegman, J., and Mégie, G.: Stratospheric profiles of nitrogen dioxide observed by Optical Spectrograph and Infrared Imager System on the Odin satellite, J. Geophys. Res., 108, D74215, doi:10.1029/2002JD002672, 2003.

Trishchenko, A. P., Li, Z., Chang, F.-L., and Barker, H.: Cloud optical depths and TOA fluxes: Comparison between satellite and surface retrievals from multiple platforms, Geophys. Res. Lett., 28, 979-982, 2001.

Tukiainen, S., Hassinen, S., Seppälä, A., Auvinen, H., Kyrölä, E., Tamminen, J., Haley, C. S., Lloyd, N., and Verronen, P. T.: Description and validation of a limb-scatter retrieval method for Odin/OSIRIS, J. Geophys. Res., 113, D04308, doi:10.1029/2007JD008591, 2008.
Vanbauce, C., Cadet, B., and Marchand, R. T.: Comparison between satellite and surface retrievals from multiple platforms, Geophys. Res. Lett., 28, 979-982, 2003.

von Savigny, C.: Retrieval of stratospheric ozone density profiles from OSIRIS scattered sunlight observations, $\mathrm{PhD}$ thesis, York University, Toronto, Canada, 2002.

von Savigny C., Haley, C. S., Sioris, C. E., McDade, I. C., Llewellyn, E. J., Degenstein, D., Evans, W. F. J., Gattinger, R. L., Griffioen, E., Kyrölä, E., Lloyd, N. D., McConnell, J. C., McLinden, C. A., Mégie, G., Murtagh, D. P., and Solheim, B.: Stratospheric ozone profiles retrieved from limb-scattered sunlight radiance spectra measured by the OSIRIS instrument on the Odin satellite, Geophys. Res. Lett., 30(14), 1755-1758, 2003.

von Savigny, C., McDade, I. C., Griffioen, E., Haley, C. S., Sioris, C. E., and Llewellyn, E. J.: Sensitivity Studies and First Validation of Stratospheric Ozone Profile Retrievals from Odin/OSIRIS Observations of limb-scattered Solar Radiation, Can. J. Phys., 83(9), 957-972, 2005a.

von Savigny, C., Rozanov, A., Bovensmann, H., Eichmann, K.-U., Noël, S., Rozanov, V., Sinnhuber, B.-M., Weber, M., Burrows, J. P., and Kaiser, J. W.: The Ozone Hole Breakup in September 2002 as Seen by SCIAMACHY on ENVISAT, J. Atmos. Sci., 62(3), 721-734, 2005b.

Wagner, T., Burrows, J. P., Deutschmann, T., Dix, B., von Friedeburg, C., Frieß, U., Hendrick, F., Heue, K.-P., Irie, H., Iwabuchi, H., Kanaya, Y., Keller, J., McLinden, C. A., Oetjen, H., Palazzi, E., Petritoli, A., Platt, U., Postylyakov, O., Pukite, J., Richter, A., van Roozendael, M., Rozanov, A., Rozanov, V., Sinreich, R., Sanghavi, S., and Wittrock, F.: Comparison of box-airmass-factors and radiances for Multiple-Axis Differential Optical Absorption Spectroscopy (MAX-DOAS) geometries calculated from different UV/visible radiative transfer models, Atmos. Chem. Phys., 7, 1809-1833, 2007, http://www.atmos-chem-phys.net/7/1809/2007/. 